Research Article

\title{
Integration of BIM and Energy Consumption Modelling for Manufacturing Prefabricated Components: A Case Study in China
}

\author{
Zhao Xu ${ }^{1},{ }^{1}$ Shaozhe Wang $\mathbb{D}^{2}{ }^{2}$ and Endong Wang ${ }^{3}$ \\ ${ }^{1}$ Department of Civil Engineering, Southeast University, Nanjing 210096, China \\ ${ }^{2}$ School of Architecture and the Built Environment, KTH Royal Institute of Technology, Stockholm, Sweden \\ ${ }^{3}$ College of Environmental Science and Forestry, State University of New York (SUNY-ESF), Syracuse, NY 13210, USA
}

Correspondence should be addressed to Zhao Xu; bernardos@163.com

Received 15 September 2019; Revised 20 October 2019; Accepted 25 October 2019; Published 14 November 2019

Academic Editor: Carlo Rainieri

Copyright (c) 2019 Zhao Xu et al. This is an open access article distributed under the Creative Commons Attribution License, which permits unrestricted use, distribution, and reproduction in any medium, provided the original work is properly cited.

\begin{abstract}
Prefabrication is undergoing significant growth in the building and construction sector in China. Meanwhile, the integrated measurement and reduction solution for energy consumption is quickly becoming an important target of scientific efforts and research, especially in prefabricated buildings. Embedded energy consumption requirements can potentially be reduced during the manufacturing process of prefabricated components: the opportunity for its reduction can be significant. This paper aims to propose a BIM and LCA integrated approach that enables the energy consumption of prefabricated components in the manufacturing stage to be extracted and calculated in order to obtain a clear, precise understanding of the energy consumption management in prefabrication. To enhance the energy consumption description of prefabricated components, this paper clarifies the contents of energy consumption inventory and related calculation formula in raw material extraction and production, material transportation, and factorized production of prefabricated components, respectively. Specifically, considering that current Industry Foundation Classes (IFC) standard does not accommodate entities with energy consumption information or relationships, it applies the IFC extension method to connect the energy consumption inventory with the BIM model. The proposed approach is applied and verified in a case study from China. This study reveals that energy consumption control should be investigated in the element level considering the differences of various prefabricated components' requirements in the manufacturing stage.
\end{abstract}

\section{Introduction}

Because of the durable operation period, large body size, and diversified participating stakeholders, building and construction sector generally consumes more energy than other ones. According to the report of Intergovernmental Panel on Climate Change, buildings comprise approximately $40 \%$ of the global energy consumption and contribute about $30 \%$ of the total global greenhouse gas emissions annually [1]. Buildings consume energy throughout all stages of their life cycle, and prefabrication has been promoted as one strategy for reducing building life cycle energy consumption [2]. Actually, prefabrication is currently undergoing significant growth in China's building and construction sector [3]. China State Council issued a policy circular specifying that prefabricated buildings will account for at least $30 \%$ of the total new construction projects in the next 10 years from 2016 [4]. From the sustainability perspective, prefabricated construction can offer significant environmental benefits, such as reduction in construction wastes, by adopting prefabricated building components during the construction stage [5], decreased green gas emissions in manufacturing activities [6], lower impacts at the end of life cycle by disassembling, and relocating instead of disposal [7].

The integrated solution to measure and reduce energy consumption is becoming an important target of scientific efforts and research, especially in building sector. The energy performance and environmental effects of traditional buildings have been previously studied; however, a limited number of works about prefabricated construction is available [3]. Peng [8] indicated that the construction, operation, and demolition of a building produce $12.6 \%, 85.4 \%$, 
and $2 \%$ of total $\mathrm{CO}_{2}$ emissions, respectively. Adalberth [9] presented case studies of total $\mathrm{CO}_{2}$ emissions of three singleunit dwellings in Sweden and found that $85 \%$ of the total energy use occurred in the operational phase, whereas the energy used for manufacturing the materials employed in construction, including erection and renovation, represented approximately $15 \%$ of the total energy use. Cao et al. [10] compared the environmental impacts of a residential prefabricated building with a traditional building through the application of life cycle assessment (LCA) in the construction stage. However, those studies have two limitations. First, embedded energy consumption requirements can potentially be reduced during the manufacturing process of prefabricated components: the opportunity for its reduction should not be ignored. A narrow boundary of the analysis on energy consumption without considering for manufacturing prefabricated components often hinders the results to be generalized to form targeted solutions for energy reduction in prefabrication. Second, limited efforts are performed in the literature review towards the energy data modelling and informatization in IFC standard.

Considering the integration of digital models and energy consumption analysis, the advent of building information modelling (BIM) offers new opportunities to further harness the efficiency of prefabricated construction [11]. BIM is a digital representation of a constructed facility [12] and offers an important line of "integration" [13], which is critical for the delivery of prefabricated construction. Previous studies were often devoted to combining BIM technology and LCA in three major directions: design scheme selection, pipeline collision, and cost evaluation. Due to the noticeable gap between BIM model and LCA software database such as Sima Pro and Gabi, using BIM data exchange standard IFC as a medium to extract energy data from BIM model for lifecycle assessment has become a key aspect for building energy consumption analysis [14]. Although a growing number of studies utilize BIM technology to support building energy consumption analysis: the challenges remain in information integration and extraction in IFC standards.

Lots of works related to building energy consumption and environmental impacts mainly focus on traditional buildings, which are constructed on-site. Another works dealing with prefabricated buildings tend to study more about the assembling and using stages of the buildings, with a limitation on the factorized manufacturing stage of all the components. When applying BIM to areas such as construction design and pipeline collision check, the possibility to optimize energy modelling and analysis with BIM has been overlooked by many studies. Differing from other works in the same area, the objective of this study is to propose a BIM and LCA integrated approach that enables the energy consumption of prefabricated components in the manufacturing stage to be extracted and calculated in order to obtain a clear and precise understanding on the energy use in prefabrication. To enhance the description of energy consumption of prefabricated components, this paper clarifies the contents of energy consumption inventory and calculation protocols for raw material production, transportation, and factorized production of prefabricated components, respectively.
Specifically, considering that the current IFC standard does not accommodate entities with energy consumption information or relationships, it applies the IFC extension method to connect the energy consumption inventory with the BIM model. The proposed approach performs more effectively and conveniently in extracting and calculating energy data while providing comprehensive, reliable data resources for energy consumption management for manufacturing prefabricated components. Finally, the proposed method was applied and verified by a case study in Nanjing, China.

\section{Literature Review}

Energy consumption analysis is one of the popular topics in sustainability studies related to different industries such as construction industry, manufacturing industry, and service industry. The production of components for prefabricated buildings belongs to the intersection of construction and manufacturing industry.

\subsection{Energy Consumption of Prefabricated Buildings. During} the development of prefabricated building, some characteristics of prefabricated building to reduce energy consumption have been suggested. Prefabrication is regarded as a cleaner production and sustainable construction approach, which has been utilized for public residential building construction to achieve more productive, safer, and higher quality construction process with less negative impacts on the environment [15]. Liu et al. [16] utilized a process-based method to assess carbon emissions during the prefabrication manufacturing process in offsite factories and designed a carbon emission benchmark for energy assessment of prefabricated buildings in China. Giovanni et al. [17] identified that prefabricated building projects have the promise for energy saving, emission reduction, process acceleration, and environment protection, and stated that prefabricated building is the future trend of green building.

LCA is a popular tool used to evaluate energy and raw material consumption, emissions, and other wastes related to a product or system's entire life cycle. Many studies were devoted in LCA and energy analysis to assist with decisionmaking processes on how to reduce prefabricated buildings' life cycle environmental impacts. Atmaca [18] proposed a model including building construction, operation, and demolition phases to estimate total energy use and $\mathrm{CO}_{2}$ emissions over 15- and 25-year life spans for container houses $(\mathrm{CH})$ and prefabricated houses $(\mathrm{PH})$, respectively. Faludi et al. [19] applied comprehensive, quantitative sustainability assessment tools to a prefabricated building application in which they have significant leverage. Monahan and Powell [20] compared the embodied carbon in a low energy, affordable house constructed using a novel offsite panelized modular timber frame system. Tao et al. [21] proposed a system based on Internet of things (IoT) technology to real-time monitor greenhouse gas emissions and energy consumption when manufacturing prefabricated components. 
2.2. Building Energy Consumption Analysis Based on BIM. Information completeness and integrity of BIM technology facilitate the cooperation and coordination between project managers and energy consumption analysts during all stages of building life cycles [22]. In order to reduce building energy consumption throughout the entire life cycle, Kang and Hong [23] proposed software architecture for the effective integration of BIM into a geographic information system (GIS)-based facilities management (FM) system.

Besides information sharing and integrated management, Ajayi et al. [24] evaluated the extent to which building material specification affects life cycle environmental performance, using a BIM-enhanced LCA methodology. Torregrosa-Jaime et al. [25] concluded that the EnergyPlus software based on BIM technology can predict the total energy consumption of the building in each year, month, or day, thus optimizing the building envelope area and heat balance during the project planning stage. As the leading building technique software, Ecotect software is released for sustainable design and building environmental impact control when combined with Revit 3D models [11], as well as the GBS (Green Building Studio) tool based on cloud computing and web services. Given the above three mostly used BIM-based energy analysis software, Reeves et al. [26] compared the strengths and weaknesses of these tools by applying them to a certain project planning stage with specific energy consumption data.

Models and tools that support the entire life cycle analysis of construction projects are limited, so it is difficult to perform the comprehensive management of the whole industrial chain, including the economic attributes, energy consumption level, and environmental impacts during planning, design, construction, and use stages of a project. To overcome this disadvantage, Andriamamonjy et al. [27] described the essential elements of the integrated workflow of BIM technology and building energy performance simulation (BEPS) and translated IFC into BEPS models to get most of the required input directly from the IFC4-file.

\subsection{Building Energy Measurement and Management System.} In order to optimize the energy consumption of construction projects, Zhang and Chen [28] developed the building energy management systems, including heating, ventilation, air conditioning, and lighting, to reduce energy consumption and increase user comfort standards at the same time. In order to increase the automation and accuracy of building energy management system, researchers such as Amarasinghe et al. [29] and Martirano et al. [30] applied computational theories including artificial neural network, fuzzy logic modelling, and evolutionary algorithms to the management systems. Moreover, Quintero and Mares demonstrated that artificial neural network can strike a balance between building thermal comfort and building energy consumption reduction after analysing a number of construction projects. Mai et al. state that building energy measurement system with radial basis function can take approximately $97 \%$ of building electrical load variability and better control the building electricity consumption. Thomas et al. [31] concluded that engineering methods including physical and thermal dynamic models, statistical methods relying on historical data and information, artificial intelligence methods including neural network and machine learning, and real-time energy test beds are the current major solutions for building energy consumption prediction and building energy system optimization.

\subsection{The Energy-Saving Practice of Prefabricated Building in} China. Since 1955, China has started to try out industrialization and mechanization of construction. From 1970s, new technology, new materials, and innovative designs for buildings have gradually developed, and the design for prefabricated buildings and the standardization of prefabricated components have been continuing to improve for more than 40 years [32]. From 1987 to 1992, China started to promote energy-saving materials, emission-reducing technology, and low energy consumption buildings in some pilot testing cities. From 1993 to 2005, China gradually developed the regulation systems, management standards, and technical supporting systems, which have taken the different climate characteristics in different areas into consideration. Since 2016, the Chinese government has released a series of policies to encourage and support the development of prefabricated building. According to the guideline, China strived to use 10 years to make more than $30 \%$ of new buildings by prefabrication, and at the same time, advocated the application of steel structures and wood structures. In March 2017, "National Action Plan for Prefabricated buildings" was released, and one year later, the Ministry of Housing and Construction proposed the application of BIM technology in various stages of prefabricated building construction to achieve energy saving.

In summary, previous studies mainly dealt with prefabricated buildings for energy performances indicator, e.g. the use of primary energy or the greenhouse gas emissions, and others are for the qualitative and quantitative measurement throughout the entire life cycle of prefabricated buildings. However, there were limited studies specifically discussing the creation and utilization of BIM and energy data to evaluate the energy consumption and saving opportunities in manufacturing prefabricated components. Information integration of prefabricated buildings is getting more complicated, and this is mainly due to the increased volume of prefabrication-related information and knowledge. This complexity and the need of reliable results claim for the utilization of existing automation tools, like BIM. The literature reviewed above identified that BIM and LCA methods are both necessary techniques in this field. Thus, developing an integrated energy consumption modelling system for manufacturing prefabricated components using BIM and LCA is key to effectively improve the sustainability of prefabricated buildings.

\section{Methodology}

This study explores to extend the interoperability of energy consumption data of prefabrication by employing the IFC data model. To achieve this, by referring to the characteristics of material, machinery, and human labour in prefabrication process, IFC data are connected with energy consumption 
inventory to form the raw data source to improve the efficiency and accuracy of energy calculation. Considering the large amount of energy consumption data created in BIM domain, we focus on two processes: (1) IFC data mapping in energy consumption domains, which include material information and energy consumption inventory. (2) Extraction and analysis of all the energy consumption data involved in prefabrication manufacture for energy modelling. Also, a case study of prefabricated building in Nanjing, China, is carried out to verify the proposed method.

The proposed method can be illustrated through the following two levels in Figure 1. The upper level represents the process of data collection, extraction, and calculation, whereas the lower level represents BIM object modelling and reading IFC data. First, the target prefabricated building is selected as the object of energy consumption analysis to provide related documents and records. Based on LCA, the targeted energy inventory is designed with a three-dimensional consideration: raw material production, material transportation, and factorized production, and then the calculation formula is proposed according to the specific design scheme of the prefabricated building. Correspondingly, in the lower level, a BIM model is created for the selected prefabricated building. In order to integrate the geometric attributes extracted from the BIM model and the energy consumption information generated in manufacturing the prefabricated components, IFC extension mechanism based on PropertySet is utilized to extend the entity attributes. Then, the database for energy consumption analysis is built to include the targeted energy inventory and associated IFC models of prefabricated components. A basic energy consumption modelling system is developed by Python programming to assist calculation and create a user interface to facilitate the operation of energy consumption analysts.

\subsection{Energy Inventory Analysis}

3.1.1. Energy Inventory Analysis. Because of the standardization and industrialization of the factorized production of prefabricated components, the characteristics of the processing procedures are similar to those of normal parts and products in ordinary industrial factories. For ordinary industrial factories, there are mainly three methods to conduct energy consumption analysis. First is to use the input and output analysis. Based on a large number of historical energy consumption statistics of the factory [33], it analyses the input level of external material and energy in factory production system, the quantitative relationship of material and energy flow among internal units, the quantity, and efficiency of product output. The second method is on-site measurement method. It mainly uses real-time measuring equipment to monitor, count, and record the fuel, power, and water consumption of various mechanical equipment used in the factory, and then calculates the energy consumption level of the whole production line [34]. The third one is energy inventory analysis based on production processes, which uses work breakdown structure (WBS) to make an energy consumption inventory for each process and calculates the total energy consumption together with the production information for all the processes [35]. Input and output analysis often requires a large number of documents and records such as the monthly and yearly electricity consumption [36]. Thus, it is more economical to be used for analysing the energy consumption of the prefabricating factory on a large scale. However, the design schemes, production plans, and schedules vary among different construction projects, which means the production situations in the prefabricating factory for different projects or even different stages for the same project can vary a lot. As a result, average-level input and output analysis of the entire factory and fixed production line is not suitable for the specific analysis of each prefabricated building. Although on-site measurement method can query historical energy consumption data, monitor and control on-site energy consumption, and obtain more accurate energy consumption data, it can easily leave out the energy consumption content, which cannot be detected by the equipment and machines, such as the energy from human labour [37].

Energy inventory analysis based on production processes method is adopted in this paper for energy data collection. It collects energy consumption data of material, machinery, and labour based on the production processes of prefabricated components to calculate the total energy consumption precisely. The perquisition to make energy consumption inventory is to define a targeted system. For prefabricated building, its entire life cycle includes the raw material production, raw material transportation, factorized production of prefabricated components, transportation of prefabricated components, on-site assembly, use, and maintenance of prefabricated building, as well as demolition of prefabricated building. The targeted system focuses on the important stages of the life cycle. Obviously, the factorized production of prefabricated components should be included in the targeted system, which is an important aspect of this paper. The energy consumed by raw material production and transportation stages should not be overlooked. As the factorized production stage of prefabricated components has already saved certain amount of energy, the energy consumption of the raw materials purchased by prefabricating factories should not be ignored. As a result, the targeted system of this paper includes stages from raw material production to the component production stage inside of prefabricating factories, which is shown in Figure 2.

\subsubsection{The Identification of Energy Inventory and the Cal-} culation Formula. According to the targeted system, the first step to make energy inventory is to identify main energy consumption categories during each stage. Specific categories are shown in the following Table 1.

After identifying the main energy consumption categories, the next step is to specify each category based on the detailed production plan, quantity, and schedule plan of prefabricated components. According to the production processes of prefabricated components and the data from different stakeholders, the material and energy flows of the production system are established, as shown in Table 2. 


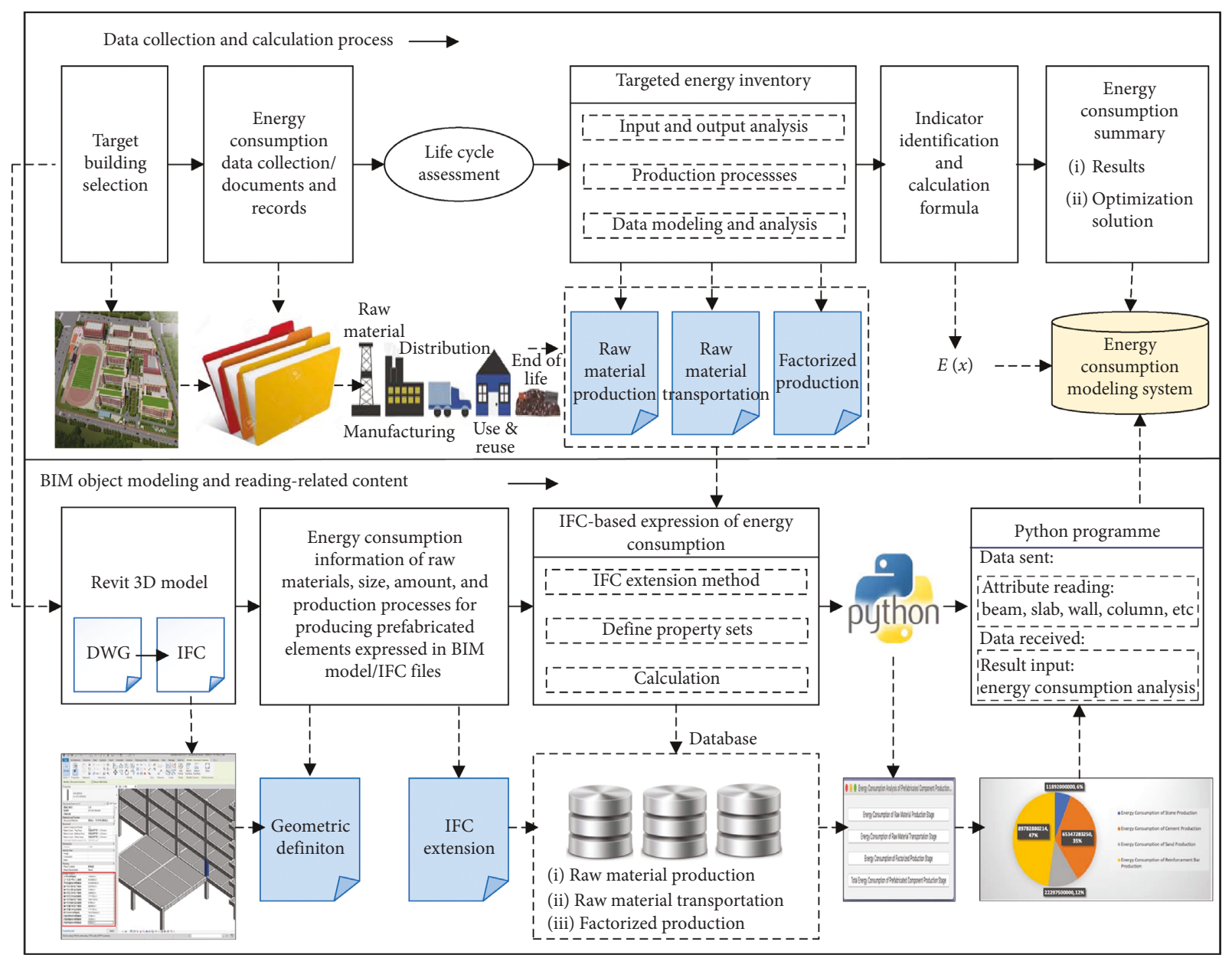

FIgURE 1: The integrated approach for energy analysis of prefabricated components.

After energy consumption inventory is identified and energy consumption data are collected, the energy consumption of prefabricated component production can be calculated, together with the information of raw material types and the needed amount. According to the specific design scheme of the prefabricated building, assuming the number of a certain kind of prefabricated component is $N$, the total volume of the component is $V\left(\mathrm{~m}^{3}\right)$, and the amount of the $i$ th raw material needed to produce $1 \mathrm{~m}^{3}$ of prefabricated component is $m_{i}(\mathrm{~kg})$, then the total energy consumption $E(\mathrm{~kJ})$ to produce each prefabricated component can be calculated according to the following formula:

$$
\begin{aligned}
E= & E_{\text {material_production }}+E_{\text {material_transportation }} \\
& +E_{\text {factorized_production }}, \\
E_{\text {material_production }}= & N \times V \times \sum_{1}^{n} m_{i} \times e_{\text {material_i}}, \\
E_{\text {material_transportation }}= & N \times V \times \sum_{1}^{n} m_{i} \times e_{\text {transport_i } i}, \\
E_{\text {factoried_production }}= & N \times V \times\left(\sum_{1}^{k} m_{\text {machine }_{-} j} \times e_{\text {human }}\right) .
\end{aligned}
$$

\subsection{IFC Extension of Energy Consumption Inventory}

3.2.1. The Benefits of BIM Technology for Energy Consumption Analysis. As is shown in the calculation formula, energy consumption inventory relies on detailed information such as the type and amount of each prefabricated component, the various locations of different raw material suppliers, all the energy related parameters of mechanical equipment, and human operating plans. The entire prefabricated building contains different types of prefabricated components, production procedures, and mechanical machines, which adds to the complication of energy consumption analysis of prefabricated component production. If the data collection and calculation are done only manually, the energy consumption analysis cannot achieve high precision and is easy to have errors.

In addition, the data needed for energy consumption calculation involve lots of stakeholders related to prefabricated buildings, such as design institutes, raw material suppliers, prefabricating factories, and delivery companies. And apparently, the involvements of these stakeholders in each phase vary dramatically. Even more, if all these involved stakeholders are located dispersedly with a temporary cooperation mechanism, the information and data communication can be very inconvenient and manual data 


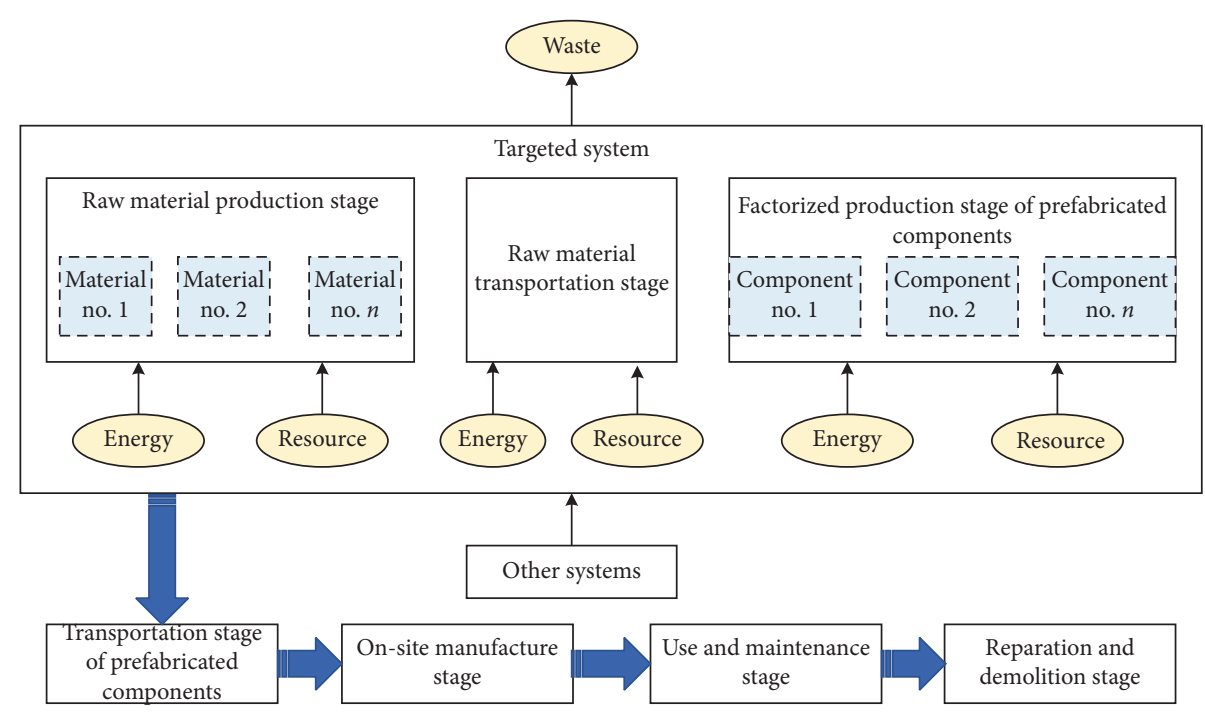

FIgURE 2: The targeted system of prefabricated components production.

TABLE 1: Main energy consumption categories of prefabricated components production.

\begin{tabular}{lr}
\hline Stage & Main energy consumption categories \\
\hline Raw material production stage & $\begin{array}{c}\text { Energy consumption of raw material extraction } \\
\text { Energy consumption of raw material manufacture }\end{array}$ \\
\hline Raw material transportation stage & Energy consumption of transportation vehicles \\
\hline $\begin{array}{l}\text { Factorized production stage of prefabricated } \\
\text { components }\end{array}$ & $\begin{array}{c}\text { Energy consumption of material processing machines } \\
\text { Energy consumption of prefabricated component } \\
\text { processing machines }\end{array}$ \\
& $\begin{array}{c}\text { Energy consumption of prefabricated component } \\
\text { transporting machines } \\
\text { Energy consumption of labour }\end{array}$ \\
\hline
\end{tabular}

TABLE 2: Energy consumption inventory of prefabricated component production.

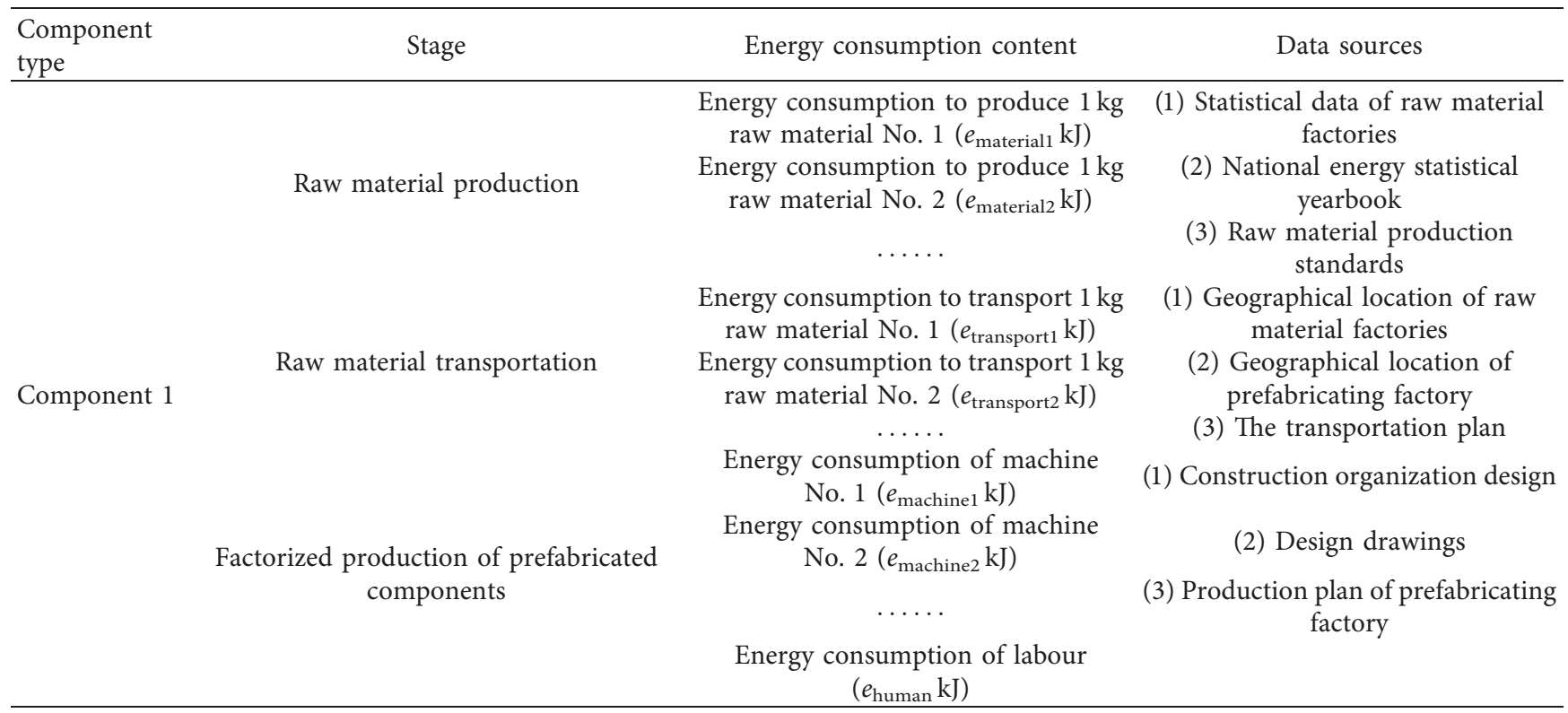


collection process increases the risk for mistakes during energy consumption data collection and calculation [35].

BIM technology realizes the digitalization of the planning, design, construction, and maintenance stages of construction projects. By connecting all kinds of information generated in the entire life cycle of buildings into a whole, BIM technology provides the informatized platform for construction management [38]. On the one hand, besides the geometric information of the design drawings, the BIM model can store other data needed for project management. For example, construction companies can share the project generic information in the BIM model, including the project location, information of stakeholders, and project managers. Design institutes can also convert 2D drawings into 3D model and use BIM model to share detail information about component attributes, reinforcement bar types, and concrete design labels at different locations in prefabricated buildings. Due to the real-time information connection provided by the BIM model, any changes made by any stakeholders can be shared automatically in the model. On the other hand, the BIM model can be the only data source for all stages of prefabricated building project, which can ensure the accuracy of data information and avoid misunderstanding. For example, prefabricating factory can extract information about types and amounts of prefabricated components, reinforcement bars, and various embedded components. For energy consumption calculation based on BIM technology, information of raw materials, size, amount, and production processing of prefabricated components can be generated by the BIM model, as is shown in Figure 3.

In this study, the energy consumption analysis protocol based on BIM is designed to fulfil two functions. (1) Energy consumption inventory can be linked with BIM framework so that each stakeholder can input related data to enrich the information contained in BIM model. (2) Researchers can extract data from different sources by BIM to conduct energy consumption calculation.

3.2.3. IFC Extension of Material Information and Energy Consumption Inventory. The connection between energy consumption inventory and BIM model is based on the IFC standard, which is being widely used in construction industry to describe construction products [39]. As an open, supplier-neutral data model, the IFC standard utilizes the object-oriented format to express the structural attributes of a building and to promote the information exchange among stakeholders involved in construction. Because of the uniformity and openness of the BIM model, the basic information, attributes, and the related data among various subprojects can be stored in "ifc" file, which can read and process information from different stakeholders from various life cycle stages [40].

Because the entities or attributes included in the current IFC standard cannot cover all the information needed for energy consumption inventory, the IFC extension of energy consumption inventory is needed. There are three main types of IFC extensions [41]: (1) If the prefabricated component needing new information does not exist in the current IFC standard, new entity should be created to perform an IFC extension. (2) If there is a corresponding entity in IFC standard that can represent the prefabricated component needing new information and the new property has been defined in that entity, the prefabricated component should be added to the predefinition of that entity to express the newly added information by connecting them. (3) If there is an entity in IFC standard for the prefabricated component, but the new property is not defined for certain entity, new property sets should be defined to conduct IFC extension. The above three types of IFC extensions are explained in Figure 4.

In the calculation formula above, the total number $(N)$ and volume $(V)$ of each prefabricated component are usually stored in BIM model when designing the drawings by CAD and Revit software. The material type and reinforcement steel amount are also added when creating model by Revit software. However, the information about raw material usually stays in the level of concrete type, which means there is no specific information about each raw material such as cement, sand, or stone. In addition, all the energy consumption contents during raw material production, transportation, and factorized prefabricated component production stages are not stored in BIM model. As a result, it is necessary to conduct IFC extension for raw material information and energy consumption inventory.

In IFC standard, the construction material information can be connected with prefabricated components by the entity IfcRelAssociatesMaterial, which means the entities IfcMaterialList and IfcMaterial can be used to add different material information for prefabricated components. The raw material amount information, such as the weight of each kind of raw material to produce $1 \mathrm{~m}^{3}$ prefabricated component, can be added in "Name" and "Description" in entity IfcMaterial. Because the properties such as weight, density, and volume have already been defined by IfcMaterialProperties, the IFC extension of raw material consumption information in this paper belongs to the first type of IFC extension. Different kinds of prefabricated components should be added into the predefinition of the entities, which have defined IfcMaterialProperties, such as IfcBeam. In the property set of IfcMaterialProperties, the property "Porosity" expresses the volume ratio of a certain prefabricated component, as is shown in Table 3.

Using the prefabricated beam as example, Figure 5 shows the IFC expression of raw material information in energy consumption inventory calculation. Solid lines represent inherited or associated relationships, whereas dashed lines represent optional relationships.

For the energy consumption data of raw material production, transportation, mechanical equipment, and human labour in prefabricating factories, no related properties exist for the already defined entity. As a result, new property sets and properties should be defined, and there are three steps: (1) Define property sets, including the name, entity, and property set description. (2) Define properties, including the name, type, and applicable value type. (3) Connect the property set with extended entity by IfcRelDefinesByProperties. Use prefabricated column as an example. The 


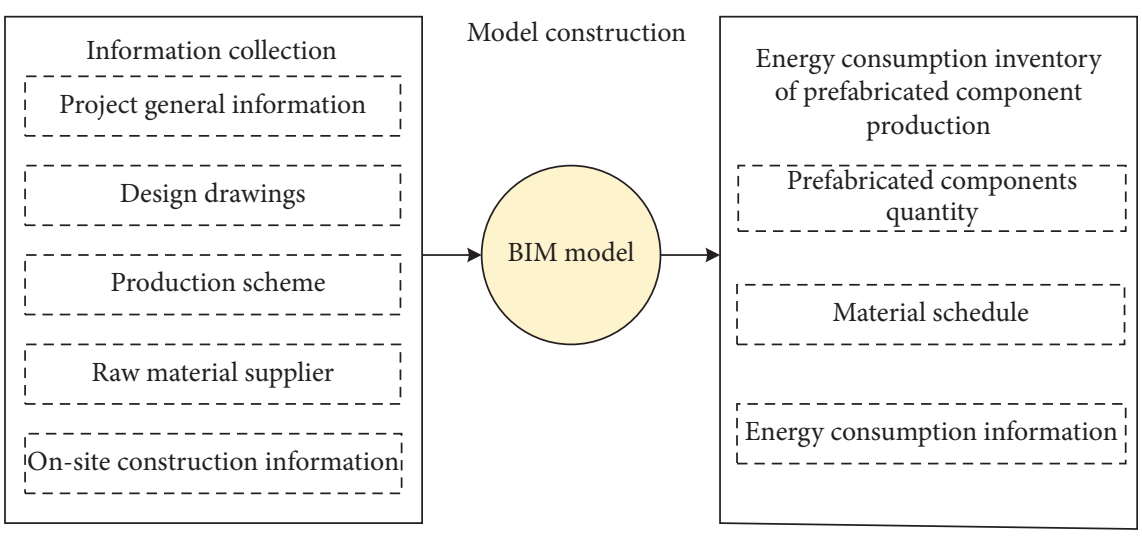

FIgURE 3: The application of BIM technology to prefabricated component production.

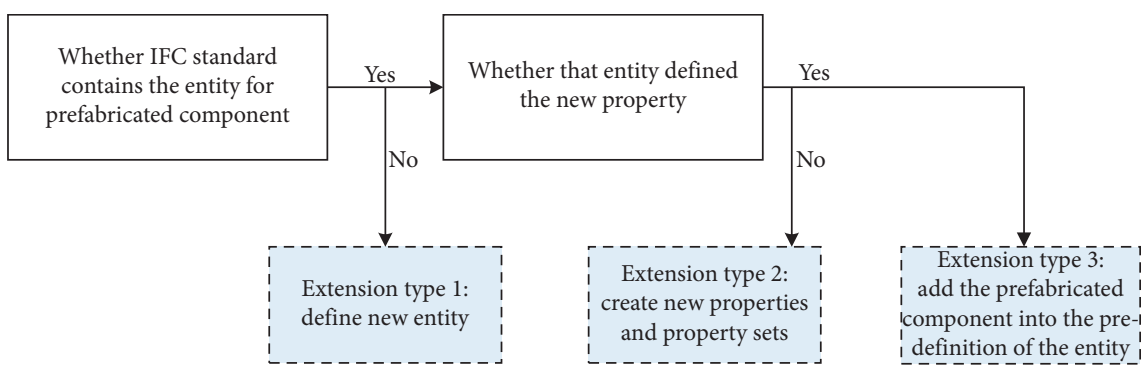

Figure 4: Three types of IFC extensions.

TABLE 3: The IFC expression of volume ratio of raw materials.

\begin{tabular}{lccc}
\hline Property & Property category & Property value type & Property definition \\
\hline Porosity & IfcPropertySingleValue & IfcNormalisedRatioMeasure & The void fraction of the total volume occupied \\
\hline
\end{tabular}

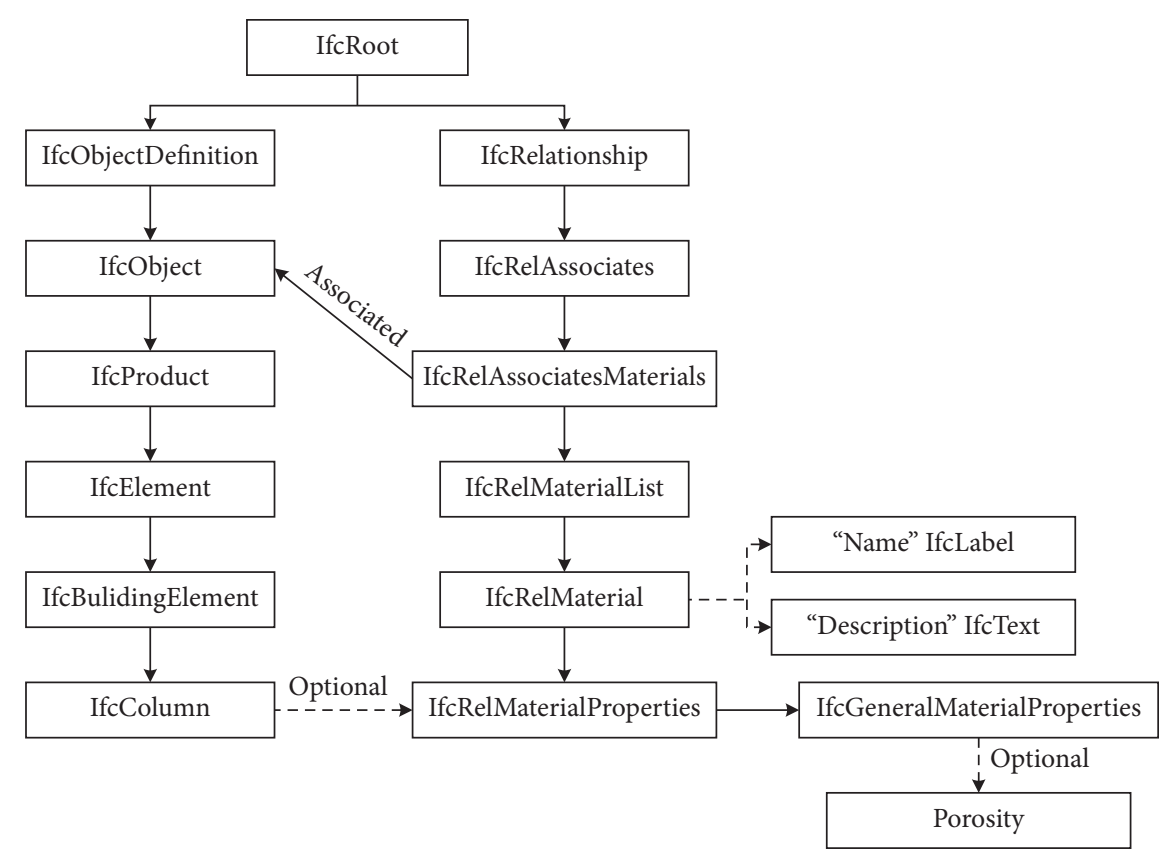

FIgURE 5: The IFC expression of raw material consumption. 
property sets for energy consumption properties during each phase of prefabricated component production are PSet_Raw Material Production Phase, PSet_Raw Material Transportation Phase, and PSet_Prefabricated Structure Factory Production Phase, as is shown in Table 4.

In the IFC standard, properties can be divided into two categories, IfcSimpleProperty and IfcComplexProperty. Because the energy consumption data in the inventory have uniformity, the new properties for energy consumption information belong to IfcSimpleProperty. As the new properties are single-valued, their value type is IfcPropertySingleValue. The definitions of new properties are shown in Table 5.

After IFC extension, the IFC expression of energy consumption of prefabricated column during each stage of its production can be seen from Figure 6.

\subsection{BIM-Based Energy Calculation. With the raw material} amount and consumption information of the prefabricated building being added, the BIM model turns into the basis for energy consumption calculation. The detailed lists of material information including the code, number and volume related to prefabricated components, the type, and amount of raw materials, as well as the energy consumption inventory including specific energy consumption data, can be exported from the BIM model. Based on the calculation formulas shown in Section 3.1.3, the energy consumption during prefabricated component production stage can be calculated. After summing up the results, the total energy consumption of all the components of the prefabricated building can be obtained.

In the actual prefabricated building project, the calculation process of energy consumption inventory often involves a lot of data, resulting from the large scale of the project, the huge variety of raw materials, and mechanical equipment. Although the calculation formula proposed above is relatively simple, manual inputs of collected data into Excel tables and manual calculations are easy to cause data omission, data misalignment, or calculation errors. Therefore, this paper considers writing a simple Python program to assist calculation and creating a user interface to facilitate the operation of energy consumption analysts. A case study will be conducted to apply theoretical method of energy consumption analysis for prefabricated component production on specific construction case. The specific steps to extract material information and energy consumption inventory, as well as the Python program, will also be shown in the case study.

\section{Case Study}

The construction project of Nanjing No. 1 Middle School is selected for a case study. The project is located in the south of Yecheng Road and east of Wuhou Street, Jianye District, Nanjing. The total construction area is $109176.71 \mathrm{~m}^{2}$, including the aboveground area of $68105.1 \mathrm{~m}^{2}$ and the underground structure area of $41071.61 \mathrm{~m}^{2}$. The project consists of three teaching buildings, a playground and grandstand, a canteen, an administrative building, a library, two dormitories, a conference room, a comprehensive building, two experimental comprehensive buildings, basement, and doorman. Specifically, teaching buildings, experimental buildings, office building, comprehensive building, and dormitory buildings adopt prefabricated integral reinforced concrete frame structure, whereas the others implement reinforced concrete frame structure.

In the main structure part of the project, beams, slabs, and columns of the basement, building nos. 5, 10, and 11 are cast-in-place, whereas the others are prefabricated structures. More specifically, the vertical components of the main structure adopt prefabricated concrete frame columns, the horizontal beams are in prefabricated concrete composites, and the floor slabs are constructed with prefabricated reinforced concrete composites. Table 6 shows the information about the number of prefabricated beams, slabs, and columns as well as the maximum weights.

\subsection{Energy Inventory for Manufacturing Prefabricated Elements}

4.1.1. Processing Flow of Prefabricated Columns. Based on the investigations of prefabricating factory, the factorized production of prefabricated columns mainly includes the manufacture and installation of moulds and steel skeletons, the preparation and pouring of concrete, and the lifting and demoulding of prefabricated columns. Among them, template cleaning, reinforcement bar processing and forming, embedded parts fixing, concrete construction and steam maintenance, mould removal, and other processes are carried out by flow-water construction method with skilled operators.

In prefabricating factory, for production processes, all the moulds are made of steel formwork. The bottom mould is first installed on the designated position according to the process layout of the factory and is then adjusted to the operation level. After the bottom mould is fixed, other moulds are assembled following the sequence from the inside, to the outside, then the bottom, and finally the above moulds. At the same time, the mould should be cleaned and the demoulding agents should be uniformly sprayed without omission.

After all kinds of reinforcement bars are transported to the prefabricating factory, they are first inspected in the entrance according to the requirements of drawing design. When the specifications, models and quality of reinforcement bars are examined, they are classified, stacked and marked. In the process of making reinforcement bar skeletons, the reinforcement sheet and installation drawing of reinforcement bar skeletons are first determined according to the design drawings, and the required specification, length, size, and quantity of reinforcement bar are determined. According to the reinforcement requirements of different parts and types of prefabricated columns, the reinforcement bars are cut and bent using the reinforcement bar cutter and bender in the prefabricating factory, respectively. Once the reinforcement bar skeletons are 
TABLE 4: Definitions of property sets of prefabricated columns production.

\begin{tabular}{lcc}
\hline Property set name & Entity & Property set definition \\
\hline PSet_Raw material production phase & IfcColumn & $\begin{array}{c}\text { This property set defines the energy consumption } \\
\text { during the production of raw materials for each } \\
\text { prefabricated structure }\end{array}$ \\
$\begin{array}{l}\text { PSet_Raw material transportation phase } \\
\begin{array}{l}\text { PSet_Prefabricated structure factory production } \\
\text { phase }\end{array}\end{array}$ & $\begin{array}{c}\text { IfcColumn } \\
\text { This property set defines the energy consumption } \\
\text { during the transportation of raw materials for each } \\
\text { prefabricated structure }\end{array}$ \\
IfcColumn & $\begin{array}{c}\text { This property set defines the energy consumption } \\
\text { during the factory production of each prefabricated } \\
\text { structure }\end{array}$ \\
\hline
\end{tabular}

TABLE 5: Definitions of properties of prefabricated column production.

\begin{tabular}{|c|c|c|c|}
\hline Energy inventory & Property name & Property category & $\begin{array}{l}\text { Value } \\
\text { type }\end{array}$ \\
\hline $\begin{array}{l}\text { Energy consumption to produce } 1 \mathrm{~kg} \text { raw } \\
\text { material No. } i\end{array}$ & $\begin{array}{l}\text { Energy consumption for material No. } i \\
\text { production }\end{array}$ & IfcPropertySingleValue & IfcReal \\
\hline $\begin{array}{l}\text { Energy consumption to transport } 1 \mathrm{~kg} \text { raw } \\
\text { material No. } i\end{array}$ & $\begin{array}{c}\text { Energy consumption for material No. } i \\
\text { transportation }\end{array}$ & IfcPropertySingleValue & IfcReal \\
\hline Energy consumption of machine No. $i$ & Energy consumption of machine No. $i$ & IfcPropertySingleValue & IfcReal \\
\hline Energy consumption of human labour & Energy consumption of human labour & IfcPropertySingleValue & IfcReal \\
\hline
\end{tabular}

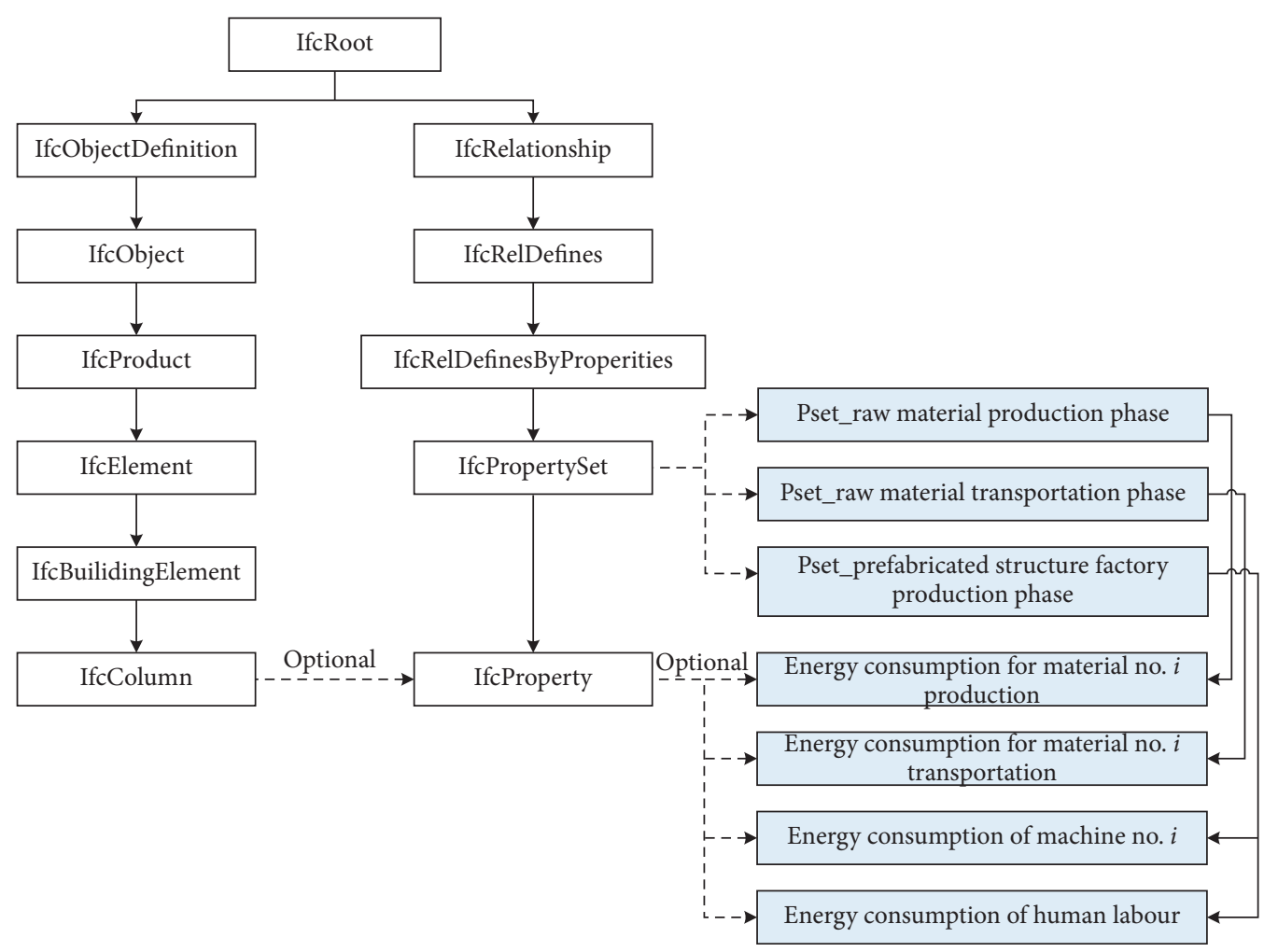

FIGURE 6: IFC expression of energy consumption of prefabricated column.

finished, they are inspected, marked, and stored for use. The mechanical equipment information used in the manufacture of reinforcement bar skeletons for prefabricated columns is shown in Table 7.

After the raw materials enter the factory, they are also tested to meet the specific acceptance criteria in terms of quality. The prefabricated columns of this project are all made of C40 concrete. In the actual production processes, the mix ratio of concrete preparation needs to be fine-tuned according to the real-time information of concrete quality and local weather conditions of prefabricating factory. At the same time, concrete slump is measured and concrete samples are made for 28-day strength examination. After preparation, concrete is poured to the fixed position of the 
TABle 6: Prefabricated components information.

\begin{tabular}{|c|c|c|c|c|c|c|c|c|c|c|c|}
\hline \multirow{2}{*}{ Type } & \multirow{2}{*}{ Maximum weight $(\mathrm{t})$} & \multicolumn{9}{|c|}{ Building number } & \multirow{2}{*}{ Tota } \\
\hline & & 1 & $2-1$ & $2-3$ & 3 & 4 & 6 & 7 & 8 & 9 & \\
\hline Beams & 4.10 & 194 & 211 & 293 & 211 & 335 & 298 & 266 & 447 & 520 & 2775 \\
\hline Slabs & 1.66 & 400 & 408 & 505 & 409 & 536 & 510 & 525 & 676 & 851 & 4820 \\
\hline Columns & 2.73 & 44 & 84 & 100 & 84 & 124 & 96 & 104 & 92 & 116 & 844 \\
\hline Total & - & 638 & 703 & 898 & 704 & 995 & 904 & 895 & 1215 & 1487 & 8439 \\
\hline
\end{tabular}

TABLE 7: Equipment information for reinforced bar skeleton manufacture.

\begin{tabular}{|c|c|c|c|}
\hline Name & Type & Supplier & Amount \\
\hline Reinforcement bar hoop bender & GF25 & Chengdu Jiedawang Machinery Co., Ltd. & 3 \\
\hline Reinforcement bar cutter & GQ50 & $\begin{array}{c}\text { Jinjian Construction Engineering Machinery Co., } \\
\text { Ltd. }\end{array}$ & 4 \\
\hline Reinforcement bar bender & GW50 & $\begin{array}{c}\text { Jinjian Construction Engineering Machinery Co., } \\
\text { Ltd. }\end{array}$ & 3 \\
\hline
\end{tabular}

component mould and concrete vibrating rod is used to vibrate for 10 to 20 seconds at each vibrating point, so as to prevent delamination or segregation. All prefabricated columns are maintained by steam within the moulds. The moulds are transported to the steam maintenance room by forklift truck. The steam curing time of each prefabricated component lasts 8 hours, and it uses gas-fired boiler. Finally, when the prefabricated columns reach $75 \%$ of the design strength, the bridge crane is used to lift the prefabricated columns from the mould and turn them over. To sum up, the above processing flow to produce prefabricated columns can be shown in Figure 7.

4.1.2. Energy Data Sources. In this project, to produce $1 \mathrm{~m}^{3}$ average prefabricated columns, about $500 \mathrm{~kg}$ of cement, $750 \mathrm{~kg}$ of sand, and $1200 \mathrm{~kg}$ of stone are needed, considering the fluctuation of mix ratio and the loss of actual production process. Table 8 reveals the average energy consumption level to produce steel bars and cement in the whole city. The energy consumption data in the table is calculated based on national standard "General rules of comprehensive energy consumption calculation standard GB/T2589-2008," which provides that $1 \mathrm{~kg}$ standard coal equivalent equals to $29307 \mathrm{~kJ}$ [43].

Energy consumption to produce sands and stones is assumed to be $600 \mathrm{~kJ} / \mathrm{kg}$ and $200 \mathrm{~kJ} / \mathrm{kg}$, respectively [44]. Because the raw material transportation for prefabricated columns involves both intracity and interprovincial transportation, and the actual transportation route is uncertain, it is assumed that the raw material transportation distance is set as 1.2 times of the linear distance between the raw material suppliers and the prefabricating factory [45]. The energy consumption of the city transport truck is $2.06 \mathrm{~kJ} /$ $\mathrm{kg} \mathrm{km}$ and of the interprovincial transportation is $3.05 \mathrm{~kJ} / \mathrm{kg}$ $\mathrm{km}$. Therefore, the energy consumption of raw material transportation stage is shown in Table 9.

During the factorized production stage of prefabricated columns, the prefabricating factory employs batch production in the form of pipeline and each mechanical equipment can process many columns at the same time. As a result, the operation time of each mechanical equipment to produce unit volume column is estimated by the relevant personnel in the factory. Then, according to the energy consumption parameters of the mechanical equipment and the "General rules of comprehensive energy consumption calculation standard GB/T2589-2008” [43], the energy consumption data of each equipment for $1 \mathrm{~m}^{3}$ prefabricated column production are shown in Table 10.

In the process of concrete maintenance, gas-fired boiler runs 24 hours a day and continues throughout the whole production process, which is 39 days long. The gas-fired boiler consumes about $280 \mathrm{~m}^{3}$ of natural gas per hour. Therefore, all the prefabricated components of this project consume about $262080 \mathrm{~m}^{3}$ of natural gas. Based on the national standard GB/T 2589-2008 that "the calorific value of $1 \mathrm{~m}^{3}$ natural gas combustion is $35544 \mathrm{~kJ}$ " [43], the energy consumption of gas-fired boiler to produce $1 \mathrm{~m}^{3}$ prefabricated column is about $7618708 \mathrm{~kJ}$. Combining with the production scale of prefabricated component plant and the energy consumption conversion stipulation of national standard GB/T 2589-2008 (the calorific value of natural gas combustion in $1 \mathrm{~m}^{3}$ is $35544 \mathrm{~kJ}$ ) [43], the energy consumption of gas-fired boiler in the production of a prefabricated component is about $7618708 \mathrm{~kJ}$.

In addition, there are 12 factory managers, 35 reinforcement workers, concrete workers, and crane operators working in the factory. Each manager works 8 hours a day and one operator works 9.5 hours a day. On average, the total manual working time for $1 \mathrm{~m}^{3}$ prefabricated column is about 10 hours. According to the research on the classification standard of physical labour conducted by Lannelongue et al. [46], construction workers consume about $4916 \mathrm{~kJ}$ of energy per eight hours of work. Therefore, the energy consumption of human labour to produce $1 \mathrm{~m}^{3}$ prefabricated column is about $(4916 / 8) * 10=6145 \mathrm{~kJ}$. Above all, the energy consumption inventory to produce prefabricated columns on the second floor of Building No. 6 in Nanjing No.1 Middle School project can be concluded in Table 11 .

4.2. IFC Expression of Energy Consumption Inventory. The IFC standard uses entities to represent prefabricated columns, and the material-related properties. As a result, the IFC extension of the information, such as material type and 
Steel bar preparation

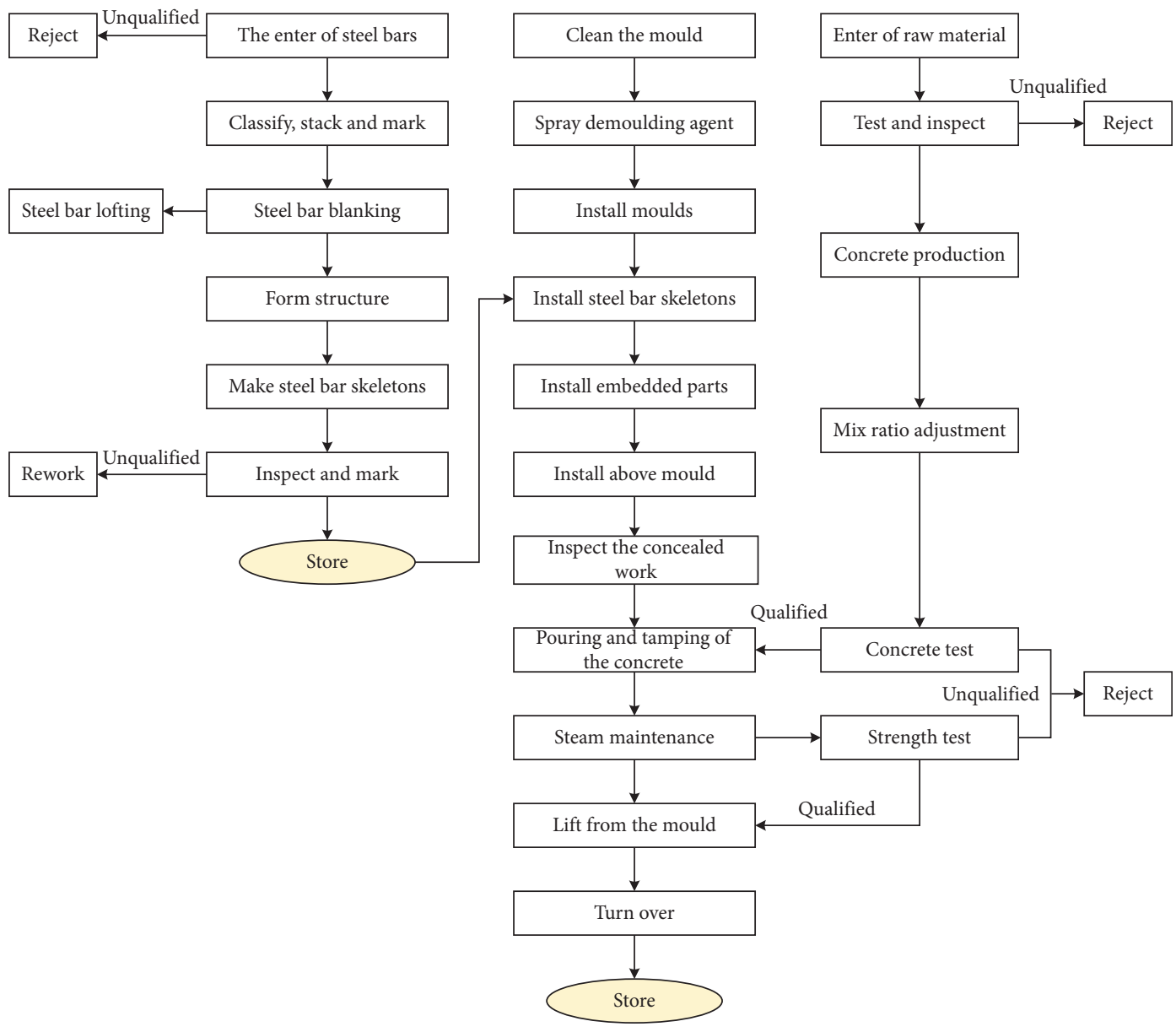

Figure 7: Processing flows to produce prefabricated columns.

TABLE 8: Energy consumption to produce cement and steel bars in Nanjing [42].

\begin{tabular}{lccc}
\hline Raw material type & Energy consumption (ton) & Energy consumption $(\mathrm{kg})$ & Converted data $(\mathrm{kJ} / \mathrm{kg})$ \\
\hline Cement & $90.11 \mathrm{~kg}$ standard coal & $0.09 \mathrm{~kg}$ standard coal & 2637.63 \\
Steel bar & $575.41 \mathrm{~kg}$ standard coal & $0.575 \mathrm{~kg}$ standard coal & 16951.53 \\
\hline
\end{tabular}

TABLE 9: Energy consumption of raw material transportation.

\begin{tabular}{lcccc}
\hline $\begin{array}{l}\text { Raw material } \\
\text { types }\end{array}$ & $\begin{array}{c}\text { Linear distance } \\
(\mathrm{km})\end{array}$ & $\begin{array}{c}\text { Estimated distance } \\
(\mathrm{km})\end{array}$ & $\begin{array}{c}\text { Energy consumption for each kilometre } \\
(\mathrm{kJ} / \mathrm{kg} \times \mathrm{km})\end{array}$ & $\begin{array}{c}\text { Energy consumption for } 1 \mathrm{~kg} \text { raw } \\
\text { material }(\mathrm{kJ} / \mathrm{kg})\end{array}$ \\
\hline Cement & 20.9 & 25.08 & 2.06 & 51.66 \\
Steel bar & 27.5 & 33 & 2.06 & 67.98 \\
Sands & 467.7 & 561.24 & 3.05 & 1711.782 \\
Stones & 467.7 & 561.24 & 3.05 & 1711.782 \\
\hline
\end{tabular}

TABLE 10: Energy consumption data of each equipment for $1 \mathrm{~m}^{3}$ prefabricated column production.

\begin{tabular}{lcccc}
\hline Equipment & Type & Energy consumption parameters & Operation time (h) & Energy consumption (kJ) \\
\hline Steel bar cutter & GQ50 & $4 \mathrm{kw}$ & 1.5 & 21.6 \\
Steel bar bender & GW50 & $7 \mathrm{kw}$ & 1 & 25.2 \\
Bridge crane & LH5-16.5A4 & The fuel consumption per shift is 25.8 kg & 3 & 412658.1 \\
Steel bar hoop bender & GF25 & $5 \mathrm{kw}$ & 1 & 18 \\
Forklift truck & CPCD50-AG55 & $86 \mathrm{kw}$ & 0.5 & 154.8 \\
\hline
\end{tabular}


TABLE 11: Energy consumption inventory of prefabricated column production.

\begin{tabular}{lcc}
\hline Prefabricated column production stages & Energy consumption contents & Energy consumption data \\
\hline & Energy consumption of cement production & $2637.63 \mathrm{~kJ} / \mathrm{kg}$ \\
Raw material production stage & Energy consumption of sand production & $600 \mathrm{~kJ} / \mathrm{kg}$ \\
& Energy consumption of stone production & $200 \mathrm{~kJ} / \mathrm{kg}$ \\
& Energy consumption of steel bar production & $16951.53 \mathrm{~kJ} / \mathrm{kg}$ \\
\hline & Energy consumption of cement transportation & $51.66 \mathrm{~kJ} / \mathrm{kg}$ \\
Raw material transportation stage & Energy consumption of sand transportation & $1711.782 \mathrm{~kJ} / \mathrm{kg}$ \\
& Energy consumption of stone transportation & $1711.782 \mathrm{~kJ} / \mathrm{kg}$ \\
& Energy consumption of steel bar transportation & $67.98 \mathrm{~kJ} / \mathrm{kg}$ \\
& Energy consumption of bridge crane & $412658.1 \mathrm{~kJ}$ \\
& Energy consumption of steel hoop bender & $18 \mathrm{~kJ}$ \\
& Energy consumption of steel cutter & $21.6 \mathrm{~kJ}$ \\
Factorized production stage & Energy consumption of steel bender & $25.2 \mathrm{~kJ}$ \\
& Energy consumption of forklift truck & $154.8 \mathrm{~kJ}$ \\
& Energy consumption of gas-fired boiler & $7618708 \mathrm{~kJ}$ \\
& Energy consumption of human labour & $6145 \mathrm{~kJ}$ \\
\hline
\end{tabular}

amount, requires the prefabricated columns to be linked with the predefinition of the corresponding entity in IFC standard, for columns is IfcColumn. Because the energy consumption information of prefabricated columns does not exist in IFC standard, new property sets and properties are needed to perform IFC extension of the energy consumption inventory for prefabricated column production. Based on the method mentioned above and the specific details of prefabricated columns on the second floor of Building No. 6 of Nanjing No. 1 Middle School project, the IFC extension of material and energy consumption information can be expressed as Figure 8.

After building the BIM model with raw material information and energy consumption inventory of Building No. 6, the detailed lists of material requirements and energy consumption data for prefabricated column production can be extracted from the model to facilitate the total energy consumption calculation. According to the national standard GB1499-2008, the density of hot-rolled ribbed bar for reinforced concrete is $0.00785 \mathrm{~kg} / \mathrm{m}^{3}$ [47]. As a result, when extracting the detailed list of material requirements, the reinforcement bar weight needs to be calculated as volume/ 0.00785 using the calculation function of Revit software. As shown in Figure 9, the data exported from Revit cover various types, large quantity, and disordered range. Meanwhile, the data needed in the energy consumption calculation formula are scattered in different columns in the following.txt file. As a result, the manual calculation of energy consumption of prefabricated component production is prone to be unreliable. In this paper, Python programming is used to automate and optimize the energy consumption calculation for prefabricated component production.

4.3. Energy Consumption Calculation Based on BIM and Python Platform. The automated energy consumption calculation module of prefabricated column production is compiled using MacOS version 10.14, Visual Studio Code version 1.33.1, and Python version 3.7.3. First, download Pip as the tool to import and manage third-party Python packages, as well as packages Numpy and PyQt5, to implement data processing and user interface design. Second, set the initial window for user interface, main window as an action, and the calculation window. Third, program for file reading and data extraction for calculation, and use functions like array addition, matrix product, matrix interproduct, and pie chart drawing for energy consumption calculation and result display. After running the program in Visual Studio Code and selecting the raw material information and energy consumption inventory files, the main window with buttons linked to different calculation functions is shown in Figure 10.

After performing energy calculation of the raw material production stage, the energy consumption of targeted prefabricated columns is calculated to be about 189319.7 MJ. Among them, the energy consumption of reinforcement bar production is about $89782.9 \mathrm{MJ}$, accounting for about half of the total energy consumption of raw materials. And the energy consumption of cement production, about 65347.3 MJ, accounts for about one-third. The production of sand and stone accounts for relatively smaller, which are about $11892 \mathrm{MJ}$ and $22298 \mathrm{MJ}$, respectively. The calculation results are shown in Figure 11.

After calculating energy consumption of the raw material transportation stage, the result is about $166676.5 \mathrm{MJ}$. Among them, the energy consumed by stone and sand transportation accounts for more than $95 \%$ of the total energy consumption in the raw material transportation stage, which are 63614.1 MJ and 101782.6 MJ, respectively. Cement and reinforcement bars consume little energy for transportation, which are about $1279.9 \mathrm{MJ}$ and 360.1 MJ, respectively. The results are shown in Figure 12.

After implementing the energy consumption calculation option for the factorized production, the energy consumption is about $398269.6 \mathrm{MJ}$, of which, the energy consumption of equipment is about 397965.1 MJ and that of human labour is only $304.5 \mathrm{MJ}$. The results are shown in Figure 13.

Finally, after choosing the option of total energy consumption for prefabricated component production, the 


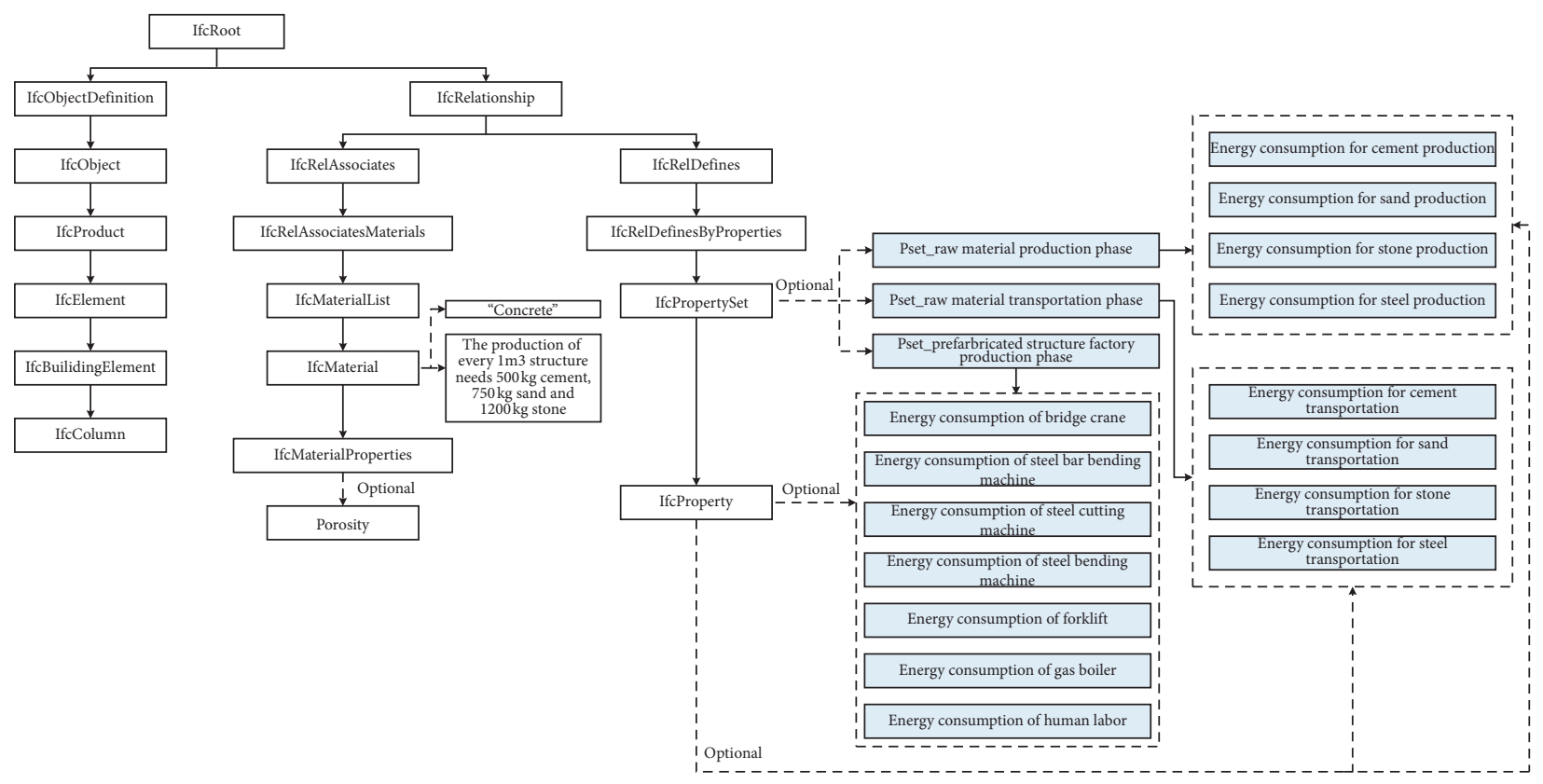

FIgURE 8: The IFC extension of material and energy consumption information.

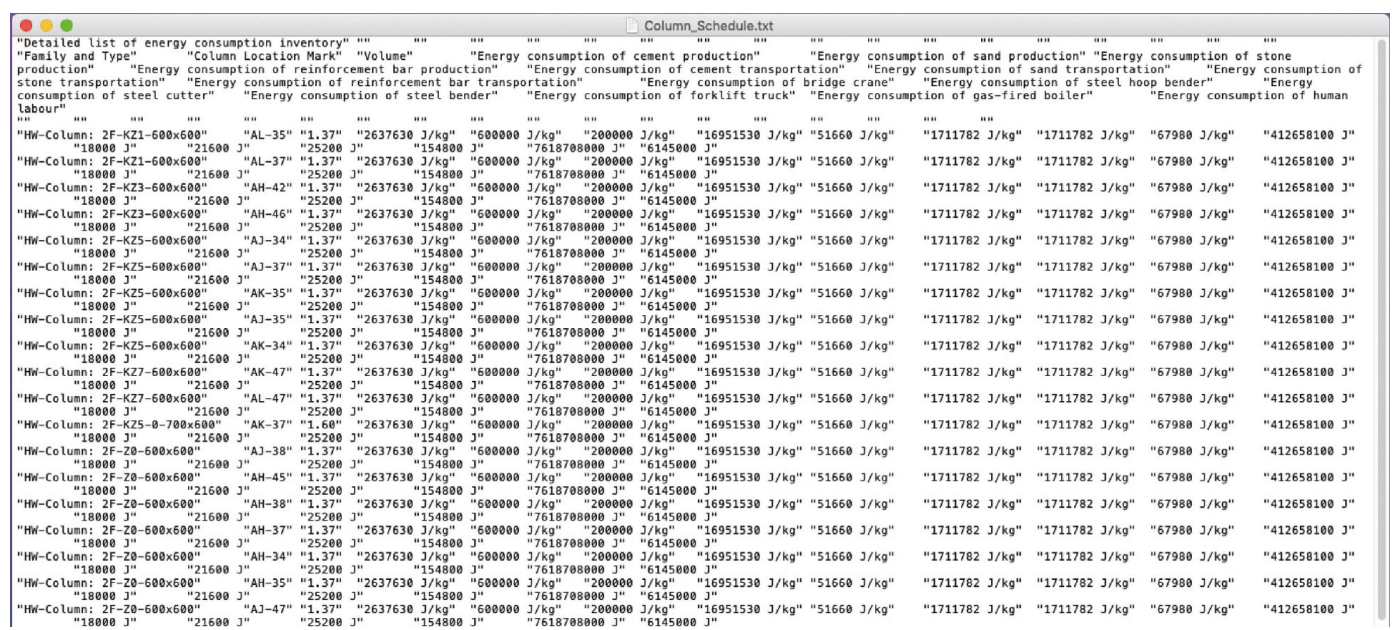

FIGURE 9: Screenshot of raw material information and energy consumption inventory.

result is about $754265.8 \mathrm{MJ}$. Among them, the energy consumption of the factorized production stage accounts for $52.8 \%$ of the total energy consumption, the raw material production stage accounts for $25.1 \%$, and the raw material transportation stage accounts for $22.1 \%$, as shown in Figure 14.

\section{Discussion}

In this case study, the production of reinforcement bar and cement production accounts for nearly $70 \%$ of the total energy consumption in the raw material production stage. The production of cold-rolled screw bars and stirrups in this project involves mechanical treatment of finished reinforcement bars such as steelmaking, cold rolling in rolling mills, straightening machines, and reinforcement bar cutters. The production of cement materials involves crushing of raw materials, preparation and mixing of raw materials, preparation of clinkers, and grinding of cement products. The preparation of stone and sand mainly involves the extraction, screening, and drying of materials. It shows that the raw material production processes of reinforcement bar and cement is more complicated than that of stone and sand, and the result of the larger proportion of total energy consumption in the production stage is reasonable.

From the calculation results of the raw material transportation stage, it is shown that the energy consumption for the transportation of stone and sand takes up more than $95 \%$ of the total energy consumption during this stage. One reason for this high energy consumption is that the supplier for stone and sand is located in Jiangxi Province, which is distant from project location. As a result, the transportation distance of stone and sand is much more than that of the other two raw materials supplied from Nanjing. Another 


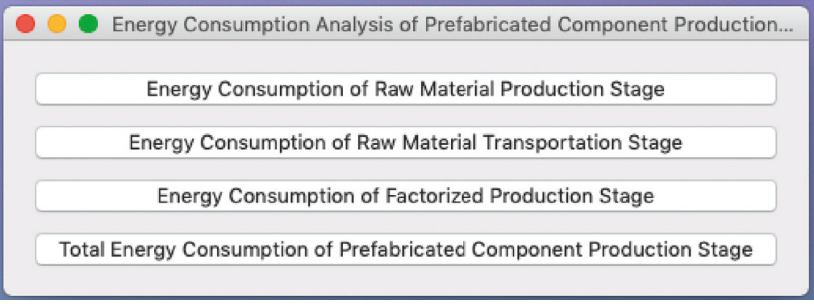

FIGURE 10: The main window of the energy consumption calculation program.

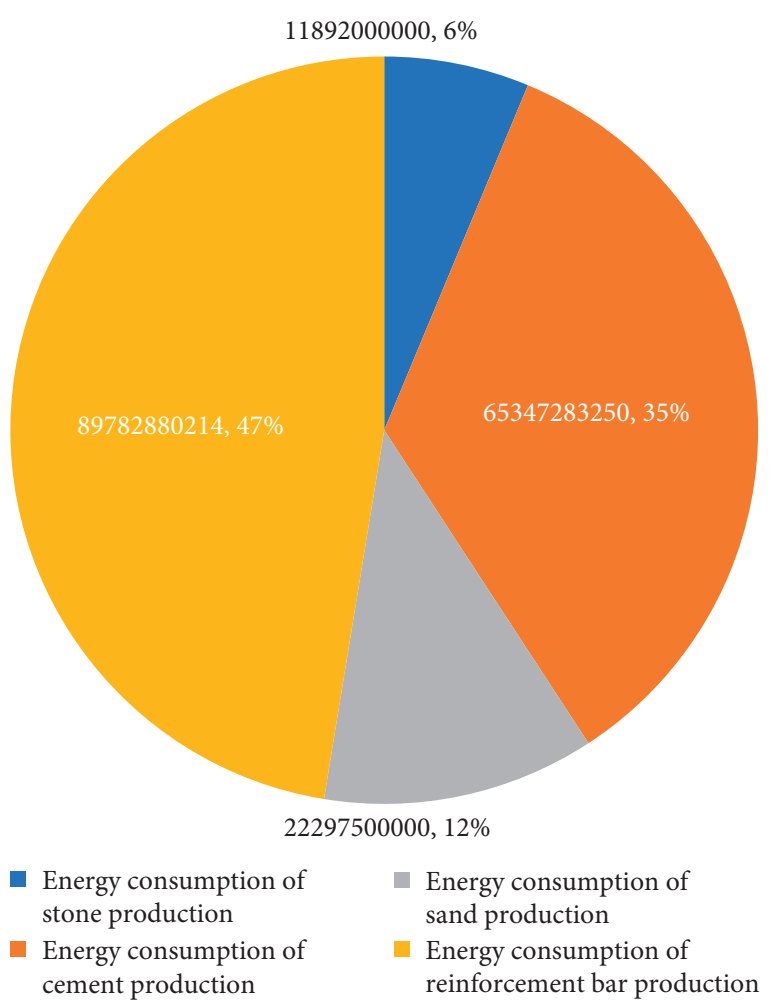

Figure 11: Energy consumption for raw material production of prefabricated columns.

reason is that interprovincial transport requires rail transit, which consumes more energy than short-distance transport trucks.

The result of energy consumption during the factorized production stage shows that nearly all the energy is consumed by equipment, which reflects the high mechanization and automation of the prefabricating factory, as well as the standardization and high efficiency of the assembly building. However, it can be noticed that the huge energy consumption of the equipment is mainly caused by bridge crane and gas boiler. Moreover, the operation of bridge crane and gas-fired boiler consumes diesel oil and natural gas, the unit energy consumption of which is much higher than that of other light equipment. The large number of bridge cranes and the long operation time of gas-fired boiler also increase the energy consumption of mechanical equipment in the prefabricating factory.

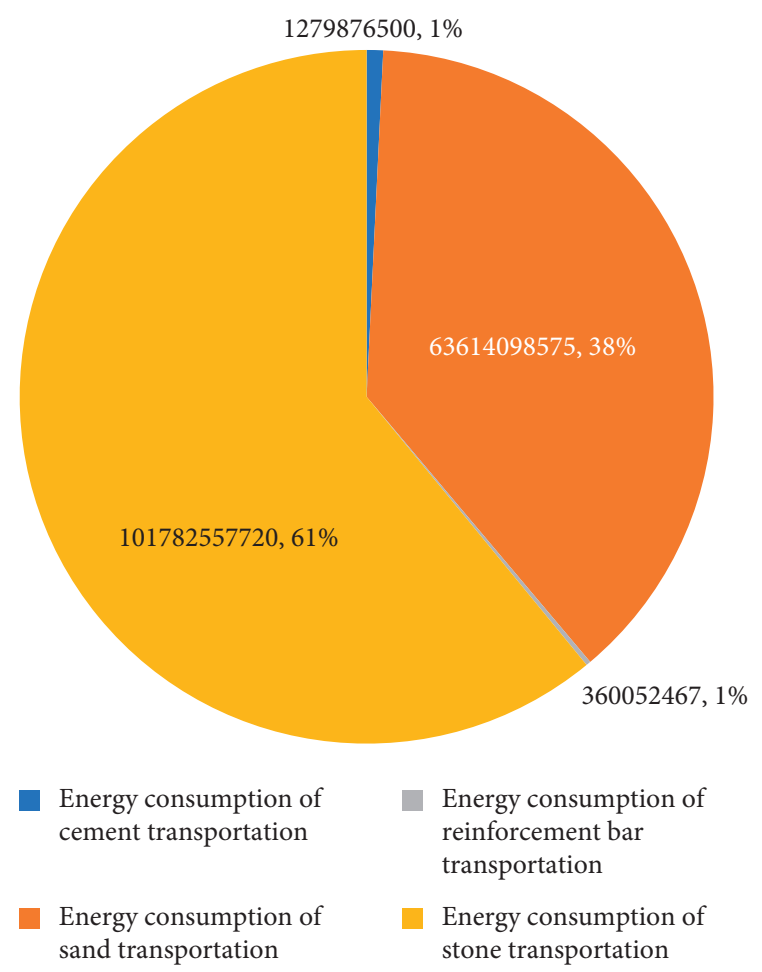

FiguRE 12: Energy consumption of raw material transportation of prefabricated columns.

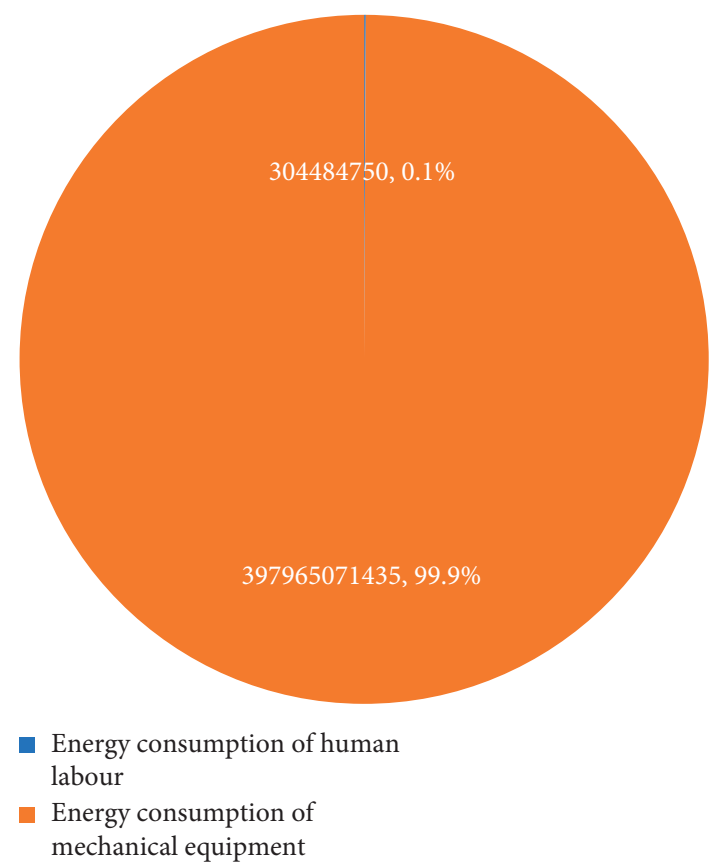

FIGURE 13: Energy consumption during factorized production of prefabricated columns.

After conducting theoretical analysis and case study related to the energy consumption model for the production stage of prefabricated buildings, this article has some limitations: (1) In real practice, the production processes for prefabricated buildings are much more complex than the 


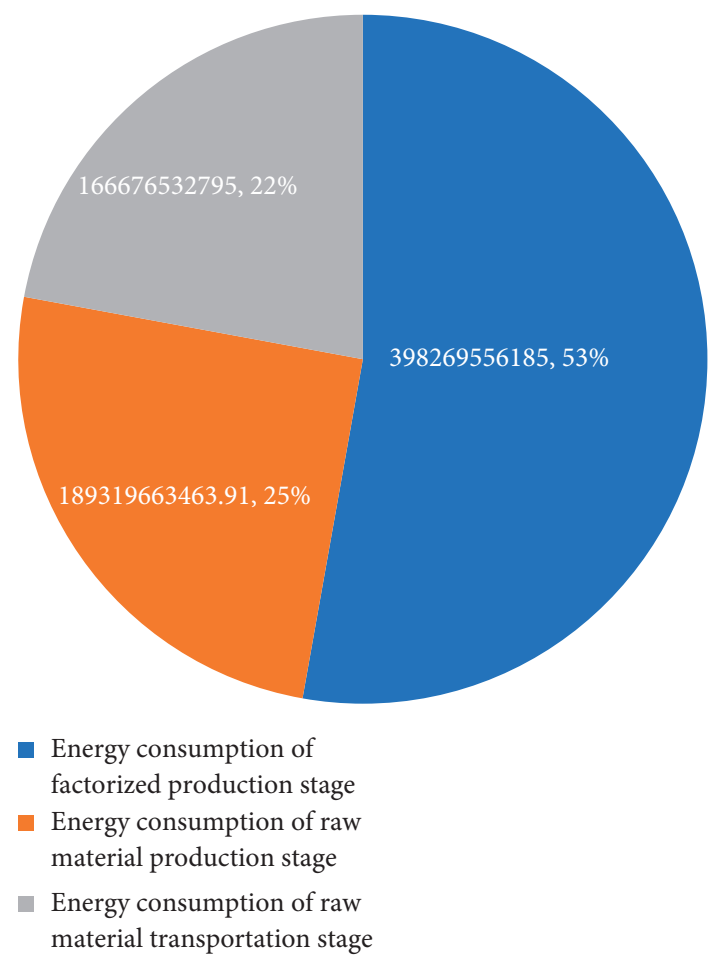

Figure 14: Total energy consumption of prefabricated column production.

three targeted stages analyzed in this article, including, for example, material storage or trading processes. Various machines and equipment are required for each process, not only in the factorized production stage. In this case, the simplification of the calculation formula in this article impacts the accuracy of energy consumption analysis. (2) The reliability of energy data collection is also worthy to discuss. On the one hand, the energy data collected from the prefabricating factory rely a lot on the project manager's experience. On the other hand, the energy data from the external literature represent the general energy consumption level instead of the specific case in this article. (3) In the case study in this article, only the columns on the second floor of Building No. 6 have been included in energy consumption calculation. For the entire project, which consists nine buildings with more than six floors each, the workload for suggested energy consumption model is still very high. In addition, the case study in this article is educational construction project, which is simpler than other types of prefabricated project such as industrial buildings. As a result, the representativeness of the specific case in this paper is not comprehensive. (4) The energy consumption model system and the IFC extension mentioned in this article are based on the mature collaboration among all the stakeholders involved in the prefabricated building project. Only if the processes such as energy data recording, BIM model improvement, and production monitoring have been conducted in detail can the energy consumption model system function well on a large scale, which means that the actual implementation of the calculation model in this paper still remains uncertain.

\section{Conclusion}

Prefabricated construction is a combination of great design with high-performance mechanisms and quality-controlled manufacturing procedures, whereas opinions on whether and to what extent prefabrication can help to reduce energy are still unclear [48] This paper explored the implementation of BIM in energy consumption analysis of prefabricated element production and proposed integrated solutions to improve energy consumption modelling with assistance of IFC extension. In order to better utilize the performance of BIM model and energy consumption inventory of prefabricated elements, a three-dimensional stage including raw material production, raw material transportation and factorized production has been proposed. Also, this paper discusses how these IFC and energy consumption data will work together to facilitate energy saving management. It helps the participants of prefabricated elements production to better understand energy consumption and to collaborate more effectively.

In this way, the IFC-integrated energy consumption modelling is effective and reliable for participants to understand energy-saving problems and track the corrective action. The benefits of the integrated solution by IFC data source and Python package proposed in this paper lie in the aspects as follows: First, the utilization of IFC extension in prefabricated building domains ensures energy information consistency and calculation precision. Furthermore, the energy inventory of prefabricated component production is identified to provide clear energy consumption definition requirements based on IFC. Typical errors caused by misunderstanding of the statistical range of the prefabricated elements can be avoided.

According to the energy consumption inventory of the prefabricated component production and the calculation results of the case, energy consumption optimization measures can be adopted in raw material production, raw material transportation, and factorized production stages of prefabricated component production. The prospects of BIM technology to optimize the energy consumption also can be spotted. In order to get more accurate energy consumption analysis, it is necessary to improve energy consumption data information of raw material production and transportation stages. It is noted that the energy consumption analysis in raw material production and transportation stages are equally as important as that of factory production and the on-site assembly stage for the prefabricated component production. Furthermore, BIM technology can be used to better provide information exchange and coediting platform for different stakeholders of the prefabricated projects. Meanwhile, the combination of BIM technology and other related software can optimize the choice of raw material transportation routes and coordinate the operation routes of different mechanical equipment in the factory, thereby realizing the energy consumption optimization of the prefabricated component production stage.

On the other hand, this study reveals that energy consumption control should be investigated in the element level considering the differences of various prefabricated 
components' requirements in the manufacturing stage. In China, a growing demand for energy has drawn increasing attention in AEC industry. Along with the continuous deepen of informatization and industrialization, a flood of enterprises and professionals are drawn to engage in prefabricated building industry. The construction of PC plants and the implementation of demonstration project have turned into the breakthrough for promoting prefabricated building in various places, especially in Shanghai, Beijing, Shenzhen, and so on. Relying on the comprehensive resources of the industry chain, some enterprises specialize in processing and supply of PC styling products and customized products. The premise is that PC market orders are sufficient or as a professional factory to achieve the overall target. Prefabricated factories should be arranged with essential energy supply to guarantee the production.

\section{Data Availability}

The data used to support the findings of this study are available from the corresponding author upon request.

\section{Conflicts of Interest}

The authors declare that there are no conflicts of interest regarding the publication of this paper.

\section{Acknowledgments}

The authors thank all survey participants and reviewers of the paper and the National Science Council of P. R. C. for financially supporting this research (NSFC-71302138).

\section{References}

[1] IPCC Intergovernmental Panel on Climate Change, IPCC Fourth Assessment Report: Climate Change 2007 (AR4), Working Group I: The Physical Science Basis, IPCC Intergovernmental Panel on Climate Change, Geneva, Switzerland, 2007.

[2] Y. Teng, K. Li, W. Pan, and T. Ng, "Reducing building life cycle carbon emissions through prefabrication: evidence from and gaps in empirical studies," Building and Environment, vol. 132, no. 15, pp. 125-136, 2018.

[3] Y. Chang, X. Li, E. Masanet, L. Zhang, Z. Huang, and R. Ries, "Unlocking the green opportunity for prefabricated buildings and construction in China," Resources, Conservation and Recycling, vol. 139, pp. 259-261, 2018.

[4] The State Council of the People's Republic of China, Guidelines on the Development of Prefabricated Buildings, The State Council of the People's Republic of China, Beijing, China, 2016.

[5] J. Hao, H. Yuan, J. Liu, C. S. Chin, and W. Lu, "A model for assessing the economic performance of construction waste reduction," Journal of Cleaner Production, vol. 232, no. 20, pp. 427-440, 2019.

[6] O. Pons and G. Wadel, "Environmental impacts of prefabricated school buildings in Catalonia," Habitat International, vol. 35, no. 4, pp. 553-563, 2011.

[7] Y. Teng and W. Pan, "Systematic embodied carbon assessment and reduction of prefabricated high-rise public residential buildings in Hong Kong," Journal of Cleaner Production, vol. 238, no. 20, Article ID 117791, 2019.

[8] C. Peng, "Calculation of a building's life cycle carbon emissions based on Ecotect and building information modeling," Journal of Cleaner Production, vol. 112, no. 1, pp. 453-465, 2016.

[9] K. Adalberth, "Energy use during the life cycle of buildings: a method," Building and Environment, vol. 32, no. 4, pp. 317320, 1997.

[10] X. Cao, X. Li, Y. Zhu, and Z. Zhang, "A comparative study of environmental performance between prefabricated and traditional residential buildings in China," Journal of Cleaner Production, vol. 109, no. 16, pp. 131-143, 2015.

[11] C. M. Eastman, P. Teicholz, R. Sacks, and K. Liston, BIM Handbook: A Guide to Building Information Modeling for Owners, Managers, Designers, Engineers and Contractors, John Wiley \& Sons, Hoboken, NJ, USA, 2011.

[12] Z. Xu, Y. Zhang, H. Li, and Q. Li, "Study on building information modeling based life cycle assessment of environmental impacts and decision making analysis for building construction," Journal of Computational and Theoretical Nanoscience, vol. 13, no. 10, pp. 7212-7225, 2016.

[13] K. Chen, W. Lu, Y. Peng, S. Rowlinson, and G. Q. Huang, "Bridging BIM and building: from a literature review to an integrated conceptual framework," International Journal of Project Management, vol. 33, no. 6, pp. 1405-1416, 2015.

[14] R. Santos, A. A. Costa, J. D. Silvestre, and L. Pyly, "Integration of LCA and LCC analysis within a BIM-based environment," Automation in Construction, vol. 103, pp. 127-149, 2019.

[15] S. Iwan, M. Hiroshi, and S. Lusi, "Household lifestyle effect on residential electrical energy consumption in Indonesia: onsite measurement methods," Urban Climate, vol. 20, pp. 2032, 2017.

[16] G. Liu, T. Gu, P. Xu, J. Hong, A. Shrestha, and I. Martek, “A production line-based carbon emission assessment model for prefabricated components in China," Journal of Cleaner Production, vol. 209, no. 1, pp. 30-39, 2019.

[17] T. Giovanni, G. Francesco, L. Sonia, F. Marco, M. Cellura, and V. Antonucci, "Life cycle energy performances and environmental impacts of a prefabricated building module," Renewable and Sustainable Energy Reviews, vol. 92, pp. 272-283, 2018.

[18] N. Atmaca, "Life-cycle assessment of post-disaster temporary housing," Building Research \& Information, vol. 45, no. 5, pp. 524-538, 2017.

[19] J. Faludi, M. D. Lepech, and G. Loisos, "Using life cycle assessment methods to guide architectural decision-making for sustainable prefabricated modular buildings," Journal of Green Building, vol. 7, no. 3, pp. 151-170, 2012.

[20] J. Monahan and J. C. Powell, "An embodied carbon and energy analysis of modern methods of construction in housing: a case study using a lifecycle assessment framework," Energy and Buildings, vol. 43, no. 1, pp. 179-188, 2011.

[21] X. Tao, C. Mao, F. Xie, G. Liu, and P. Xu, "Greenhouse gas emission monitoring system for manufacturing prefabricated components," Automation in Construction, vol. 93, pp. 361374, 2018.

[22] Z. Cheng, S. N. Raja, and T. Lu, "BIM-based investigation of total energy consumption in delivering building products," Advanced Engineering Informatics, vol. 38, pp. 370-380, 2018.

[23] T. W. Kang and C. H. Hong, "A study on software architecture for effective BIM/GIS-based facility management data integration," Automation in Construction, vol. 54, pp. 25-38, 2015. 
[24] S. O. Ajayi, L. O. Oyedele, B. Ceranic, M. Gallanagh, and K. O. Kadiri, "Life cycle environmental performance of material specification: a BIM-enhanced comparative assessment," International Journal of Sustainable Building Technology and Urban Development, vol. 6, no. 1, pp. 14-24, 2015.

[25] B. Torregrosa-Jaime, P. J. Martínez, B. González, and G. PayáBallester, "Modelling of a variable refrigerant flow system in energy plus for building energy simulation in an open building information modelling environment," Energies, vol. 12, no. 1, pp. 22-38, 2018.

[26] T. Reeves, S. Olbina, and R. Issa, "Validation of building energy modeling tools: ecotect ${ }^{\mathrm{TM}}$, green building studio ${ }^{\mathrm{TM}}$ and IES," in Proceedings of the Winter Simulation Conference, December 2012.

[27] A. Andriamamonjy, D. Saelens, and R. Klein, “An automated IFC-based workflow for building energy performance simulation with Modelica," Automation in Construction, vol. 91, pp. 166-181, 2018.

[28] Y. Zhang and Q. Chen, "Prediction of building energy consumption based on PSO-RBF neural network," in Proceedings of the 2014 IEEE International Conference on System Science and Engineering, July 2014.

[29] K. Amarasinghe, D. Wijayasekara, H. Carey, D. He, and W.-P. Chen, "Artificial neural networks based thermal energy storage control for buildings," in Proceedings of the 41st Annual Conference of the IEEE Industrial Electronics Society, November 2015.

[30] L. Martirano, G. Parise, L. Parise, and M. Manganelli, "Simulation and sensitivity analysis of a fuzzy-based building automation control system," in Proceedings of the 2014 IEEE Industry Application Society Annual Meeting, October 2014.

[31] A. Thomas, C. C. Menassa, and V. R. Kamat, "An LCM framework to couple spatially distributed energy simulation and occupancy models for optimizing building energy consumption," in Proceedings of the Construction Research Congress, May 2016.

[32] X. X. Li and G. L. Li, "Exploration of modular build of architectural space," Applied Mechanics and Materials, vol. 357-360, pp. 338-344, 2013.

[33] T. Hawkins, C. Hendrickson, C. Higgins, H. S. Matthews, and S. Sangwon, "A mixed-unit input-output model for environmental life-cycle assessment and material flow analysis," Environmental Science \& Technology, vol. 41, no. 3, pp. 1024-1031, 2007.

[34] K. Whitlock, F. H. Abanda, M. B. Manjia, C. Pettang, and G. E. Nkeng, "BIM for construction site logistics management," Journal of Engineering, Project, and Production Management, vol. 8, no. 1, pp. 47-55, 2018.

[35] Y. Lu, Z. Huang, and T. Zhang, "Method and case study of quantitative uncertainty analysis in building energy consumption inventories," Energy and Buildings, vol. 57, pp. 193-198, 2013.

[36] S. Liao, X. Liu, and Z. Rao, "Sensitivity analysis of energy consumption in industrial production processes based on input-output model," Journal of Tongji University, vol. 45, no. 3, pp. 427-433, 2017.

[37] D. Gong, Y. Huang, Y. Zhang et al., "Production scheduling optimization of shaft machine parts based on energy consumption analysis," Light Industry Machinery, vol. 35, no. 5, pp. 91-95, 2017.

[38] T. Tan, K. Chen, F. Xue, and W. Lu, "Barriers to Building Information Modeling (BIM) implementation in China's prefabricated construction: an interpretive structural modeling
(ISM) approach,” Journal of Cleaner Production, vol. 219, pp. 949-959, 2019.

[39] Z. Ma, Z. Wei, S. Wu, and L. Zhe, "Application and extension of the IFC standard in construction cost estimating for tendering in China," Automation in Construction, vol. 20, no. 2, pp. 196-204, 2011.

[40] Z. Ma, Z. Wei, and X. Zhang, "Semi-automatic and specification-compliant cost estimation for tendering of building projects based on IFC data of design model," Automation in Construction, vol. 30, pp. 126-135, 2013.

[41] M. F. Muller, F. Esmanioto, N. Huber, E. R. Loures, and O. Canciglieri, "A systematic literature review of interoperability in the green building information modeling lifecycle," Journal of Cleaner Production, vol. 223, no. 20, pp. 397-412, 2019.

[42] Nanjing Statistical Bureau, "The unit consumption of more than half of high energy consumption products in Nanjing decreased," 2019, http://tjj.nanjing.gov.cn/tjxx/201902/t20190226_ 1435277.html.

[43] State Bureau of Technical Supervision of the People's Republic of China, General Principles for Computing Comprehensive Energy Consumption GB/T 2589-2008, China Standards Publishing House, Beijing, China, 2008.

[44] Globalmarketers, Global Silica Sand Industry Market Research Report, Maia Research Publish, 2018.

[45] A. Ahmadian, A. Akbarnezhad, T. H. Rashidi, and S.T. Waller, "Importance of planning for the transport stage in procurement of construction materials," in Proceedings of the 31st International Symposium on Automation and Robotics in Construction and Mining (ISARC), pp. 466-473, Sydney, Australia, July 2014.

[46] G. Lannelongue, J. Gonzalez-Benito, and I. Quiroz, "Environmental management and labour productivity: the moderating role of capital intensity," Journal of Environmental Management, vol. 190, no. 1, pp. 158-169, 2017.

[47] State Bureau of Technical Supervision of the People's Republic of China, National Standards of the People's Republic of China GB1499-2008, China Standards Publishing House, Beijing, China, 2008.

[48] S. Azhar, W. A. Carlton, D. Olsen, and I. Ahmad, "Building information modeling for sustainable design and LEED ${ }^{\circledR}$ rating analysis," Automation in Construction, vol. 20, no. 2, pp. 217-224, 2011. 


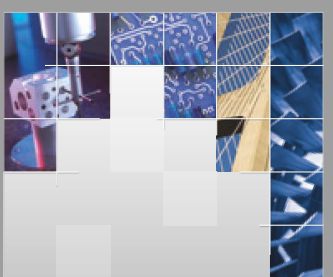

\section{Enfincering}
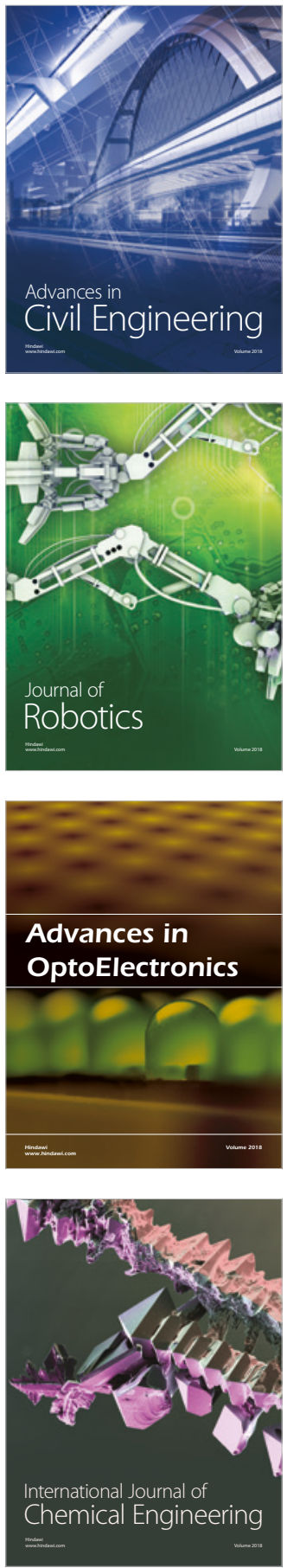

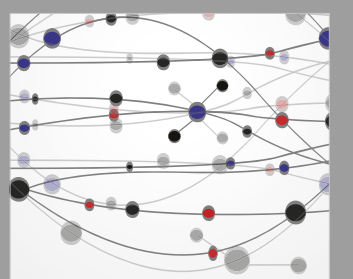

\section{Rotating \\ Machinery}

The Scientific World Journal

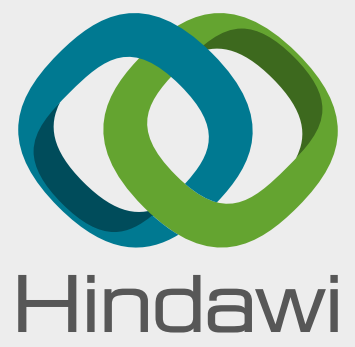

Submit your manuscripts at

www.hindawi.com
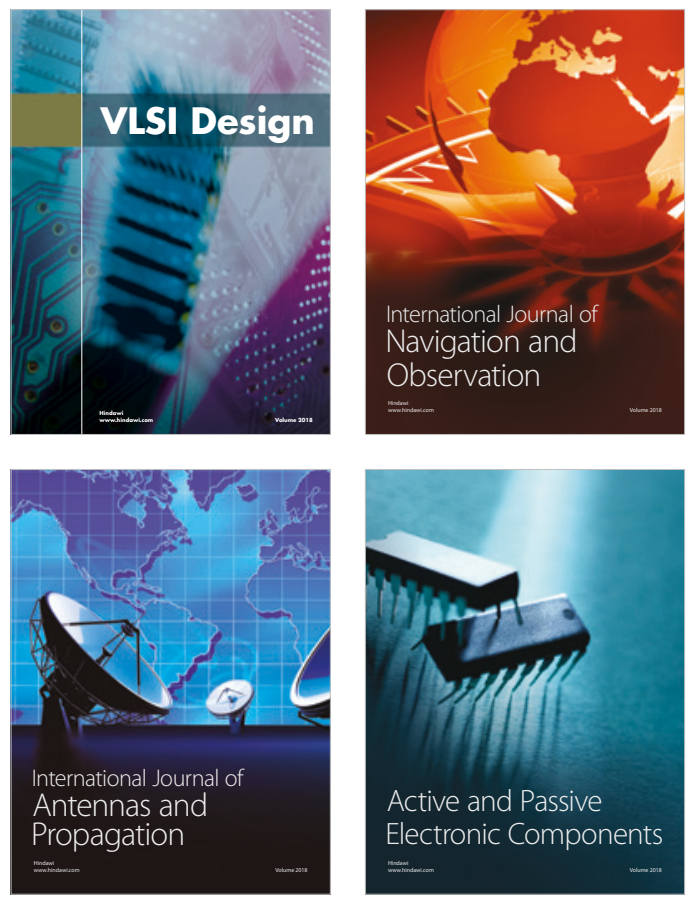
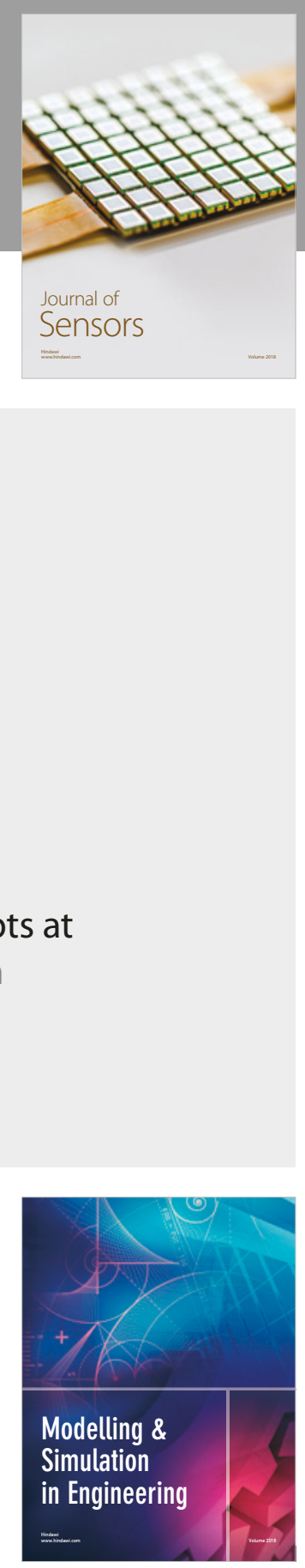

\section{Advances \\ Multimedia}
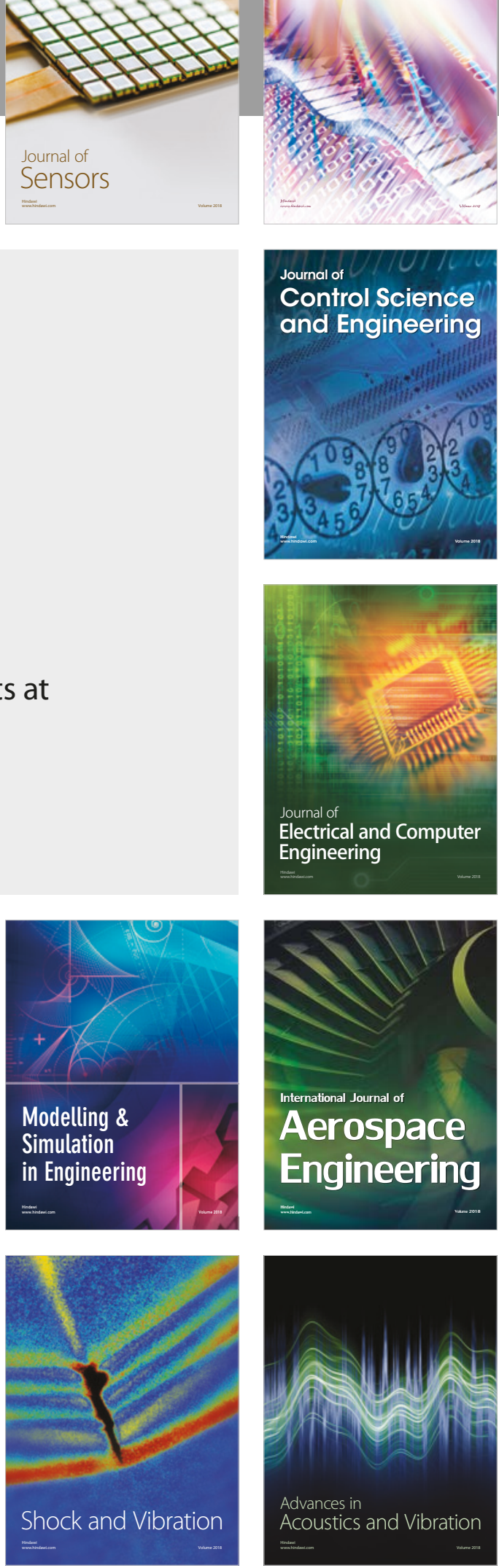